Geosci. Model Dev. Discuss., 4, 343-384, 2011

www.geosci-model-dev-discuss.net/4/343/2011/

doi:10.5194/gmdd-4-343-2011

(c) Author(s) 2011. CC Attribution 3.0 License.

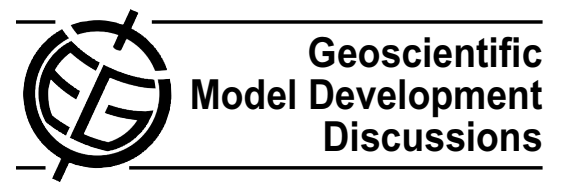

GMDD

4, 343-384, 2011

This discussion paper is/has been under review for the journal Geoscientific Model

Development (GMD). Please refer to the corresponding final paper in GMD if available.

\title{
Ground-level ozone concentration over Spain: an application of Kalman Filter post-processing to reduce model uncertainties
}

V. Sicardi ${ }^{1}$, J. Ortiz ${ }^{1}$, A. Rincón ${ }^{1}$, O. Jorba ${ }^{1}$, M. T. Pay ${ }^{1}$, S. Gassó ${ }^{1,2}$, and J. M. Baldasano ${ }^{1,2}$

${ }^{1}$ Barcelona Supercomputing Center - Centro Nacional de Supercomputación, Spain ${ }^{2}$ Laboratory of Environmental Modeling, Universitat Politècnica de Catalunya (LMA-UPC), Spain

Received: 1 February 2011 - Accepted: 4 February 2011 - Published: 15 February 2011 Correspondence to: V. Sicardi (vsicardi@bsc.es)

Published by Copernicus Publications on behalf of the European Geosciences Union.

Ground-level ozone concentration over Spain

V. Sicardi et al.

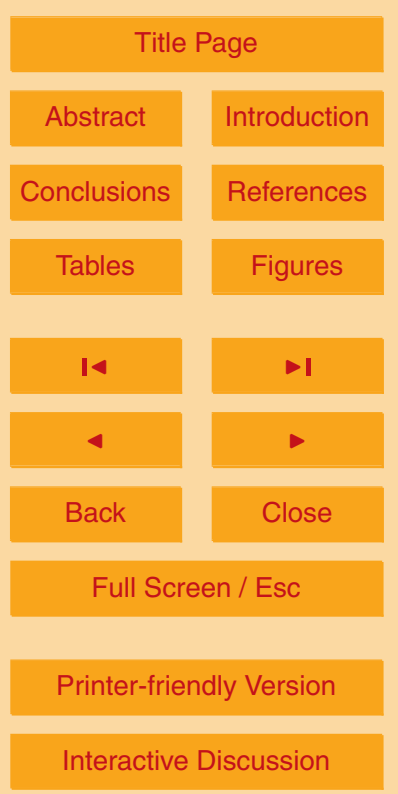




\section{Abstract}

The CALIOPE air quality modelling system, namely WRF-ARW/HERMESEMEP/CMAQ/BSC-DREAM8b, has been used to perform the simulation of ground level $\mathrm{O}_{3}$ concentration for the year 2004, over the Iberian Peninsula. We use this system to

5 study the daily ground-level $\mathrm{O}_{3}$ maximum. We investigate the use of a post-processing such as the Kalman Filter bias-adjustment technique to improve the simulated $\mathrm{O}_{3}$ maximum. The Kalman Filter bias-adjustment technique is a recursive algorithm to optimally estimate bias-adjustment terms from previous measurements and model results. The bias-adjustment technique is found to improve the simulated $\mathrm{O}_{3}$ maximum for the entire year and the whole domain. The corrected simulation presents improvements in statistical indicators such as correlation, root mean square error, mean bias, standard deviation, and gross error. After the post-processing the exceedances of $\mathrm{O}_{3}$ concentration limits, as established by the European Directive 2008/50/CE, are better reproduced and the uncertainty of the modelling system is reduced from $20 \%$ to $7.5 \%$. Such uncertainty in the model results is under the established EU limit of the $50 \%$. Significant improvements in the $\mathrm{O}_{3}$ average daily cycle and in its amplitude are also observed after the post-processing. The systematic improvements in the $\mathrm{O}_{3}$ maximum simulations suggest that the Kalman Filter post-processing method is a suitable technique to reproduce accurate estimate of ground-level $\mathrm{O}_{3}$ concentration.

\section{Introduction}

Ozone pollution is one of the main concerns in Europe and in particular in the Mediterranean area (Baldasano et al., 1994, 2003; Millán et al., 1997; Gangoiti et al., 2001; Gerasopoulos et al., 2005; Jiménez et al., 2005a, 2006; Cristofanelli and Bonasoni, 2009). Meteorological factors affect the $\mathrm{O}_{3}$ concentrations and in Spain, due to the prevailing meteorological stable conditions, the emissions patterns, and the topography, the $\mathrm{O}_{3}$ pollution is a crucial, but already addressed problem (Millán et al., 2002;

GMDD

4, 343-384, 2011

\section{Ground-level ozone concentration over Spain}

V. Sicardi et al.

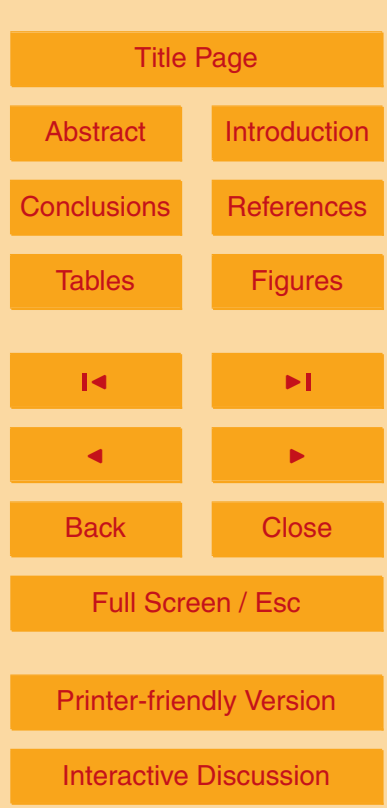

Interactive Discussion 
Jiménez and Baldasano, 2004; Jiménez et al., 2005b, 2008). Elevated concentrations of tropospheric $\mathrm{O}_{3}$ may lead to adverse effects on human health, agricultural crops, forests and materials (Brauer et al., 1997; West et al., 2007; WHO, 2008; FinlaysonPitts, 2010).

The European air quality Directive 2008/50/EC defines target values and long-term objectives for the protection of human health and vegetation. The objective target value for human health protection is $120 \mathrm{\mu g} \mathrm{m}^{-3}$ (calculated as daily maximum averaged over $8 \mathrm{~h}$ running mean) and is not to be exceeded on more than 25 days per year averaged over $3 \mathrm{yr}$. The information threshold must be given to the population when hourly means 10 exceed $180 \mathrm{\mu g} \mathrm{m}^{-3}$, and the alert threshold should be issued if hourly means exceed $240 \mathrm{~g} \mathrm{~m} \mathrm{~m}^{-3}$. Modelling techniques are valid and recognized means to monitor and predict the air quality and the reliability of such models is essential.

The air quality CALIOPE system, namely WRF-ARW/HERMES-EMEP/CMAQ/BSCDREAM8b, operatively applied under the Spanish government founded project 15 CALIOPE (Baldasano et al., 2008a) has been used to perform hindcasts of tropospheric $\mathrm{O}_{3}$ over Spain for the year 2004. The CALIOPE modelling system has been used in previous studies to assess the air quality over Europe and Spain (Pay et al., 2010; Baldasano et al., 2010). Comparisons of $\mathrm{O}_{3}$ model results with observations have revealed that even though the temporal variability in $\mathrm{O}_{3}$ is well simulated, further improvement in the $\mathrm{O}_{3}$ simulations are still needed.

In order to produce more accurate simulations, we post-process the model results with a bias-adjustment technique (Kang et al., 2008). We carry out the simulation of ground level $\mathrm{O}_{3}$ concentration over Spain, for the year 2004, and analyze the results produced by the modelling system (hereafter model results) and after the application of Kalman Filter bias-adjustment technique (hereafter KF-output). The Kalman Filter (Kalman, 1960), already applied in previous studies of atmospheric pollution modelling, reduces the error in the model results by the application of recent bias of the forecast and observations to produce an adjusted forecast (Delle Monache et al., 2006; Kang et al., 2008, 2010). The Kalman Filter is a versatile and rapid bias-adjustment
GMDD

4, 343-384, 2011

\section{Ground-level ozone concentration over Spain}

V. Sicardi et al.

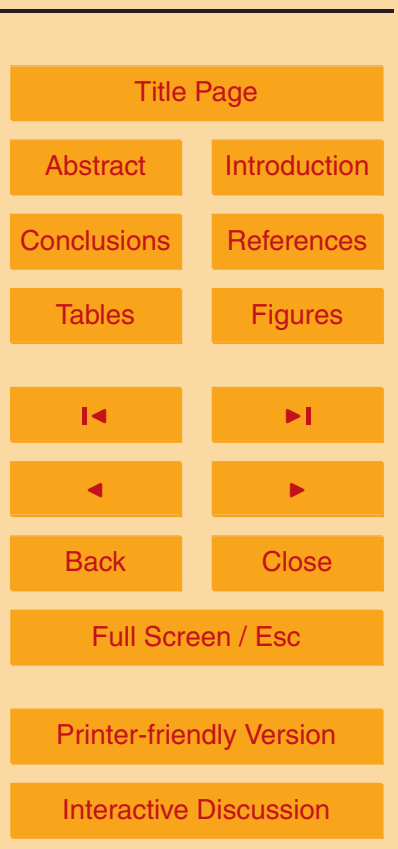


technique that is applied to point stations and when observations are available. Both the model results and KF-output are tested over a set of stations located throughout the domain. Models always have uncertainties due to the data limitations and incomplete representation of the physical/chemical mechanisms; this introduces errors in the 5 model results (Borrego, 2003; Chang and Hanna, 2004; Flemming and Stern, 2007). The uncertainty of the model results is calculated and checked against the European Directive 2008/50/CE; hence, the improvement achieved by the post-process is verified. An analysis of the main statistical parameters is also carried out together with an analysis of the daily cycle and their improvement achieved by the application of the o post-processing.

In this work we investigate the reliability of the CALIOPE air quality system in reproducing $\mathrm{O}_{3}$ daily maximum, the improvements in the $\mathrm{O}_{3}$ simulation and the reduction of the model uncertainties after the post-processing. This paper is organized as follow: Sect. 2 contains a model overview and a description of the air quality observation 15 network; in Sect. 3 is introduced the Kalman Filter and the uncertainty calculation. In Sect. 4 are presented the results and in Sect. 5 the conclusions.

\section{Methods}

\subsection{Modelling system}

The CALIOPE air quality modelling system is a state-of-the-art modelling framework (www.bsc.es/caliope). It is a complex system that integrates the meteorological model: WRF-ARW; the emission model: HERMES; the chemical transport model: CMAQ; and the mineral dust atmospheric model: BSC-DREAM8b offline coupled in an air quality forecasting system (Baldasano et al., 2008a).

The Advanced Research Weather Research and Forecasting (WRF-ARW) model v3.0.1.1 (Michalakes et al., 2004; Skamarock et al., 2005; Skamarock and Klemp, 2008) provides the meteorology conditions. For the Iberian Peninsula (IP) domain

\section{GMDD}

4, 343-384, 2011

\section{Ground-level ozone concentration over Spain}

V. Sicardi et al.

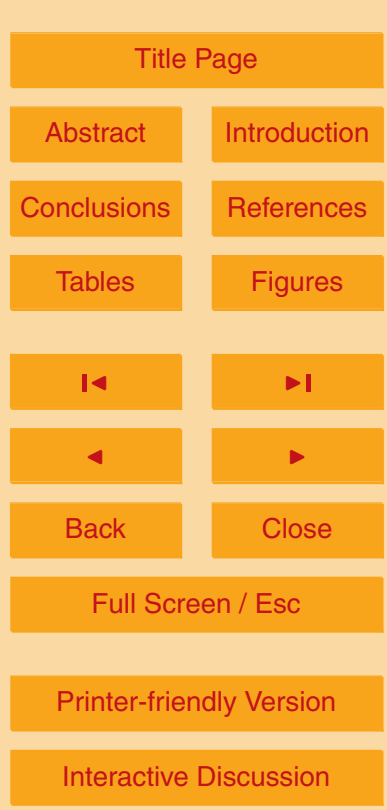

Interactive Discussion 
WRF-ARW is configured with a grid of $397 \times 397$ points corresponding to a $4 \mathrm{~km} \times 4 \mathrm{~km}$ horizontal resolution and $38 \sigma$ vertical levels with 11 characterizing the planetary boundary layer (PBL). The model top is defined at $50 \mathrm{hPa}$ to resolve the tropospherestratosphere exchanges.

5 The Models-3 Community Multiscale Air Quality Modelling System (Models-3/CMAQ, Byun and Ching, 1999; Binkowski, 1999; Byun and Schere, 2006), v4.5 is used to study the behavior of air pollutants from regional to local scales. It includes gas, aerosol and heterogeneous chemistry. According to Jiménez et al. (2003) the gas-phase chemistry mechanism used is the Carbon Bond IV (CBM-IV, Gery et al., 1989). The version of 10 CBM-IV mechanism is that presented in CMAQv4.5 original code (Appel et al., 2007) which introduces some changes and updates in the original CBM-IV mechanism such as an updating isoprene chemistry to Carter's one product form (Carter, 2000) and an inclusion of gaseous species that are necessary to link gas-phase chemistry to aerosol formation. The aerosols are modeled using the AERO4 module (Binkowski and Roselle, 2003). Secondary inorganic aerosols (SIA) are generated by nucleation processes from their precursors to form nitrate ammonium and sulfate aerosols. The thermodynamic equilibrium between gas and inorganic fine aerosols is determined by the ISORROPIA model (Nenes et al., 1998).

The CMAQ horizontal grid resolution corresponds to that of WRF. Its vertical struc20 ture was obtained by a collapse from the 38 WRF layers to a total of 15 layers steadily increasing from the surface up to $50 \mathrm{hPa}$ with a stronger density within the PBL. In order to provide adequate boundary and initial conditions to the IP domain the CALIOPE modelling system was initially run on a regional scale $(12 \mathrm{~km} \times 12 \mathrm{~km}$ in space and $1 \mathrm{~h}$ in time) to model the European domain (mother domain). Chemical boundary conditions for this domain were provided by the global climate chemistry model LMDzINCA2 (Hauglustaine et al., 2004; Folberth et al., 2006). A one-way nesting was then performed to retrieve the meteorological and chemical conditions for the IP domain (Fig. 1).
GMDD

4, 343-384, 2011

\section{Ground-level ozone concentration over Spain}

V. Sicardi et al.

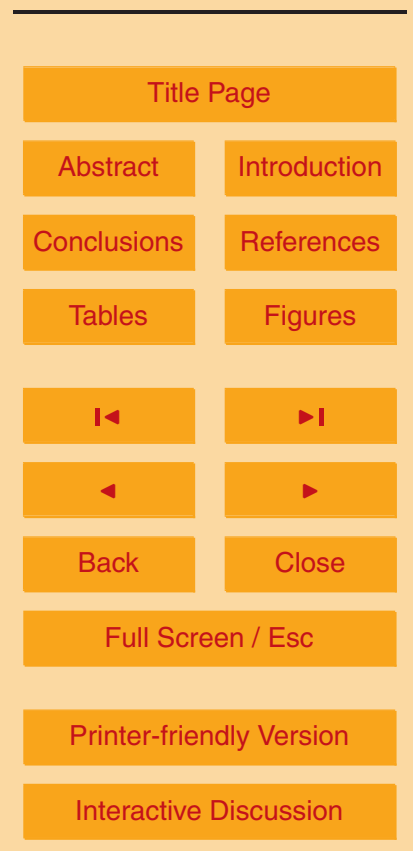


The HERMES model (Baldasano et al., 2008b) uses information and state-of-theart methodologies for emission estimations. It calculates emissions by sector-specific sources or by individual installations and stacks. Emissions used for Spain are derived from the aggregation in space from $1 \mathrm{~km} \times 1 \mathrm{~km}$ dataset to $4 \mathrm{~km} \times 4 \mathrm{~km}$. Raw emission 5 data are processed by HERMES in order to provide a comprehensive description of the emissions to the air quality model. In this study the emissions are expressed in CBM-IV speciation. Regarding to biogenic emissions, HERMES calculates the biogenic volatile organic compounds (bVOC) from vegetation. Three categories of bVOC are estimated according to their reactivity: isoprene, monoterpenes and other volatile 10 organic compounds (OVOC). The model considers the influence of temperature and photosynthetically active radiation (PAR) by Guenther et al. (1995) algorithms, according to Parra et al. $(2004,2006)$. Emission factors for each individual vegetal species are associated with emitter land-use categories. The land-use categories for each grid cell are obtained from CORINE Land Cover 2000 map starting with a resolution of

$100 \mathrm{~m}$, and adapting to 22 the land-use categories according to Arévalo et al. (2004). In the updated version of HERMES model used in the present work, the influence of seasonality in the emission of bVOC is introduced through an environmental correction factor following Staudt et al. (2000) and Steinbrecher et al. (2009).

The Dust REgional Atmospheric Model (BSC-DREAM8b) was designed to simulate and predict the atmospheric cycle of mineral dust (Nickovic et al., 2001; Pérez et al., $2006 a, b)$. The domain considered in this study comprises northern Africa, the Mediterranean basin and Europe. BSC-DREAM8b is fully embedded within the NCEP/Eta meteorological driver (Janjic, 1994). It simulates the long-range transport of mineral dust at a $0.3^{\circ} \times 0.3^{\circ}$ resolution using 24 vertical layers extending up to $15 \mathrm{~km}$ in altitude on an hourly basis. The aerosol description contains 8 bins to allow a fine description of dust aerosols. Dust-radiation interactions are calculated online. An offline coupling is applied to the calculated concentrations of particulate matter from CMAQ (Jiménez et al., 2008).
GMDD

4, 343-384, 2011

\section{Ground-level ozone concentration over Spain}

V. Sicardi et al.

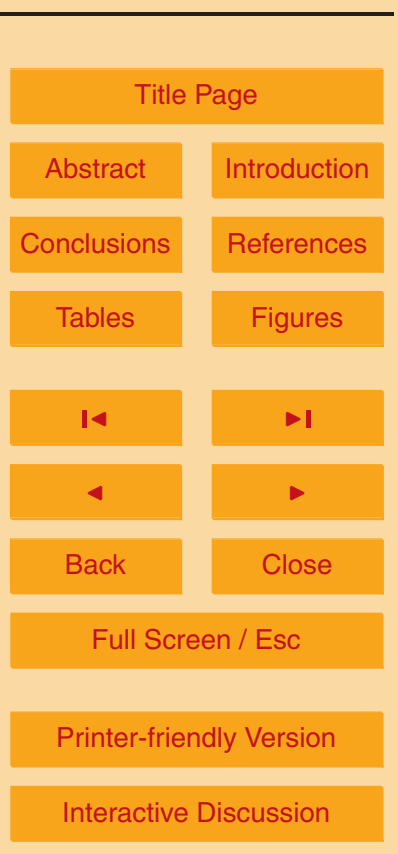


This modelling system has been evaluated in depth; a detailed evaluation of the European domain is presented in Pay et al. (2010), and for the IP domain in Baldasano et al. (2010). For a detailed description of the evaluation of this system we refer to these studies. The simulation has been carried out for the full year 2004 and for the 5 same period has been done the statistical analysis of the model skills. For the daily cycle analysis, only the data from the ozone campaign (April to September) have been analyzed. The ground level $\mathrm{O}_{3}$ concentration has been taken into account as representative of the surface concentration and compared with observations.

\subsection{Observations}

10 The model simulations are tested against the hourly observations from a network of 82 stations (hereafter referred as RedESP) covering the entire Spanish territory (Fig. 1). The hourly measurements provided by "Centro de Estudios Ambientales del Mediterraneo (CEAM)", were subjected by a preliminary quality control. Monitoring data were available for the full year 2004 , but only stations with temporal coverage of $85 \%$ were taken into account and compared with the model results. The temporal minimum data coverage of $90 \%$ as recommended in the Directive $2008 / 50 / E C$, refers to the data without calibration and maintenance, thus it reduces to minimum data coverage of $85 \%$ after the quality control (Garber et al., 2002).

The air quality monitoring stations are classified as urban, suburban and rural according to their locations (Garber et al., 2002; Annex III of the Directive 2008/50/EC). To extract the model results corresponding to the stations considered we apply two procedures: for the urban and suburban station the mean value of the corresponding $4 \times 4 \mathrm{~km}$ grid cell has been taken. For the rural stations it has been done a bilinear interpolation with the closest cells. All the statistics are calculated for all the stations and no weight has been given to the different stations type. We compute the daily maximum of the hourly data (max. 1-h) and the daily maximum of the $8 \mathrm{~h}$ running average (max. 8-h) for each station over the full year and compare them with the observations. When computing the daily maximum, for both hourly and 8-h averaged data, only the days

GMDD

4, 343-384, 2011

\section{Ground-level ozone concentration over Spain}

V. Sicardi et al.

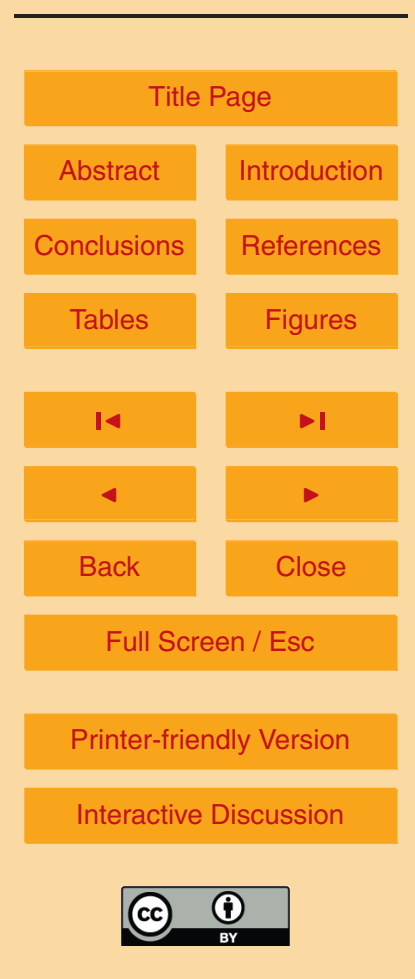


with a minimum of $75 \%$ of hourly data have been taken into account (according to the Spanish project to national law for air quality, 2010). Following this criterion 24 days of the entire year have been eliminated in the case of the max. 1-h calculation and 27 days in the case of max. 8-h calculation.

\section{Post - processing and uncertainty}

\subsection{The Kalman Filter}

The model results have been post-processed by the application of the Kalman Filter Predictor. The Kalman Filter Predictor is a post-processing method that uses recent estimates and measurements to revise and improve the current estimate (Kalman, 1960)

10 and it has been applied in previous $\mathrm{O}_{3}$ studies (Delle Monache et al., 2006, 2008; Kang et al., 2008). In Kang et al. (2008) a thorough discussion about the error ratio is presented and it is demonstrated that even though the optimal error ratios vary in space, the impact of using different optimal values over the model domain on the resultant bias-adjusted forecast was insignificant when compared to a representative fixed value for all locations. To test whether the same conclusion is valid for our $\mathrm{O}_{3}$ simulation, error ratios ranging from 0.01 to 2 have been selected for all the stations considered over the entire year 2004. Root mean square error and correlation coefficient values have been calculated to gauge the impact of spatially different error ratio values on the performance (Fig. 2). Based on this approach we finally use an optimal value varying seasonally for all the stations (Table 1 ).

When using seasonally varying values, the $\mathrm{O}_{3}$ simulation is found to improve. Nevertheless, it is assessed that $\mathrm{O}_{3}$ simulation over different areas (e.g. rural versus urban), or for different model results may have different optimal ratio values (Delle Monache et al., 2006; Kang et al., 2010).

It is also worth noting that the Kalman Filter is applied only to discrete points (monitoring stations) and then an average is taken to have a representation of the whole
GMDD

4, 343-384, 2011

\section{Ground-level ozone concentration over Spain}

V. Sicardi et al.

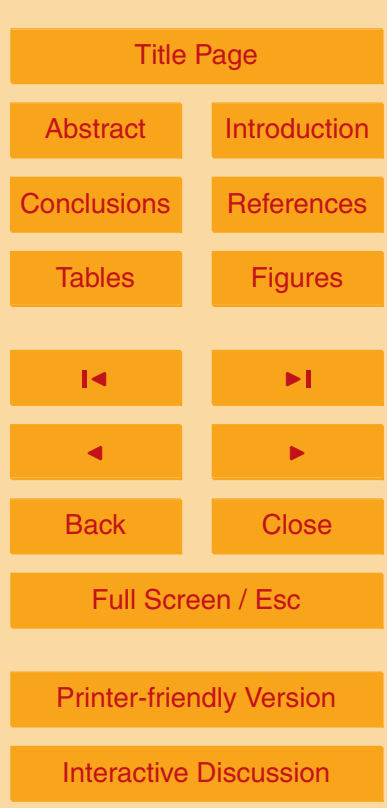


domain. The complexity of the domain and the difference in emissions sources over the domain suggest that, further research is needed to extend the correction to the whole domain (Kang et al., 2010).

\subsection{Uncertainty and statistics}

5 The model uncertainties can be associated with model formulation regarding misrepresentation of atmospheric dynamics and chemistry, numerical solutions, choice of modelling domain and grid structure; with the model input regarding emissions, meteorological data; or with the stochastic processes that are not known (Borrego et al., 2008; Chang and Hanna, 2004).

Reducing the uncertainties is fundamental in order to obtain high quality model results. In the European Directive 2008/59/CE, "the uncertainty for modelling is defined as the maximum deviation of the measured and calculated concentration levels for $90 \%$ of individual monitoring points, over the period considered, by the limit value (or target value in the case of ozone) without taking into account the timing of the events. The uncertainty for modelling shall be interpreted as being applicable in the region of the appropriate limit value (or target value in the case of ozone). The fixed measurements that have to be selected for comparison with modelling results shall be representative of the scale covered by the model". The "without timing" in the above definition, implies that the time factor is not taken into consideration, nor the sequences of the events (e.g. when an exceedance of concentration limit occurs), which is fundamental in the case of air quality forecast systems.

The Guidance on the use of models for the European air quality directive proposes the statistic calculations needed to validate the air quality models and their related uncertainties (Denby et al., 2010). The uncertainty calculated for a single station is

$\mathrm{RDE}=\frac{O_{\mathrm{LV}}-M_{\mathrm{LV}}}{\mathrm{LV}}$

GMDD

4, 343-384, 2011

\section{Ground-level ozone concentration over Spain}

V. Sicardi et al.

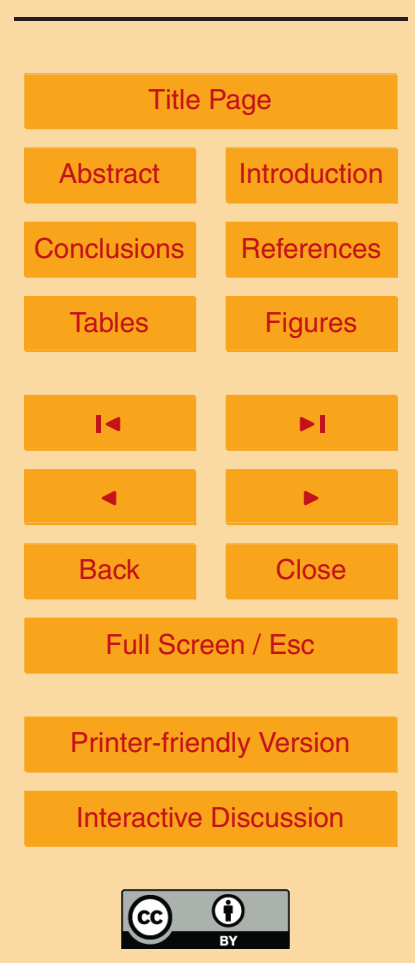


Where $O_{\mathrm{LV}}$ is the closest observed concentration to the limit value concentration (LV) and $M_{\mathrm{LV}}$ is the corresponding ranked modelled concentration. The maximum of this value found at $90 \%$ of the available stations is then the Maximum Relative Directive Error (MRDE). The MRDE represents the uncertainty of the model in the evaluation 5 of the air quality. The Directive considers that the model uncertainty related to the $\mathrm{O}_{3}$ simulation must be $\leq 50 \%$; therefore models with uncertainty minor to $50 \%$ will meet the EU directive requirements. The Directive also requires an uncertainty $\leq 50 \%$ for measurements.

The model skills are evaluated over the maximum hourly (max. 1-h) and 8-h running 10 mean $\mathrm{O}_{3}$ concentration (max. 8-h) in order to verify the ability of the model to reproduce the day-by-day maximum variation. The model skills are also evaluated over the mean daily cycle, as average of all the available days of concentration for the $24 \mathrm{~h}$, in order to verify the ability to capture the day to night variations (Appel et al., 2007; van Loon et al., 2007; Vautard et al., 2007). In addition, the exceedance of the threshold concentration has been considered by the analysis of a contingency table. All the statistics are calculated over the full year 2004; the daily cycle is analyzed only for the $\mathrm{O}_{3}$ campaign (April to September).

The model evaluation is carried out using classical statistical indicators for the ground level daily maximum 1-h and 8- $\mathrm{h}_{3}$ concentration (Dennis et al., 2010). Namely the statistic metrics used are: Mean Bias (MB) as a measure of model bias, the Root Mean Square Error (RMSE) as measures of model error, the correlation coefficient (COR) as measure of the agreement between model and observations, and the Standard Deviation of the error $\left(S D_{e r}\right)$ as measure of the uncertainty. The latter parameter has been computed starting from the hourly errors (hourly model concentrations minus observations) for every station and for these values it is calculated the standard deviation.

Additionally we compute the Mean Normalize Bias Error (MNBE) and the Mean Normalized Gross Error (MNGE) according to the model evaluation objectives suggested by the United States Environmental Protection Agency (US-EPA). The US-EPA in the "Guidance on the Development, Evaluation, and Application of Environmental models"

GMDD

4, 343-384, 2011

\section{Ground-level ozone concentration over Spain}

V. Sicardi et al.

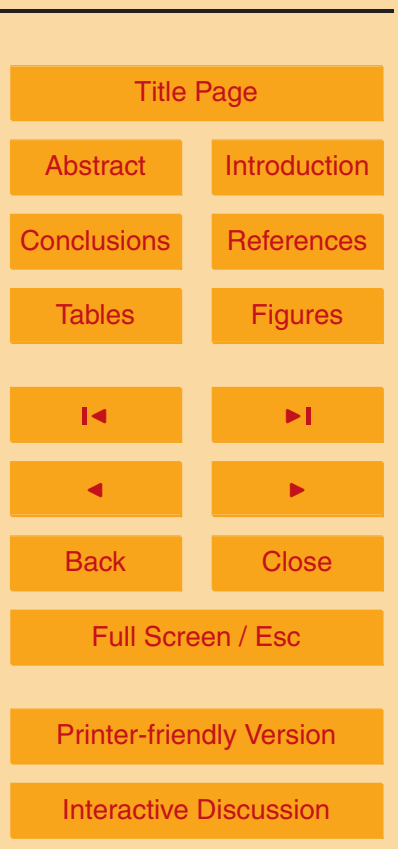

Interactive Discussion 
(US-EPA 2009) presents recommendations and provides an overview of best practices for ensuring and evaluating the quality of environmental models. The US-EPA establishes that these parameters should be: MNBE $\leq 15 \%$ and MNGE $\leq 35 \%$ (US-EPA, 1991, 1997, 2007, 2009).

$5 \quad$ The categorical statistical skills are also evaluated (Kang et al., 2005, Eder et al., 2006), by calculating the Accuracy $(A)$, which measures the fraction of exceedances and no-exceedances correctly predicted; the Bias $(B)$, which measures if there are under-predictions or over-predictions; the Probability of Detection (POD), which measures what fraction of the exceedances are correctly predicted; the False Alarm Ratio 10 (FAR), which measures what fraction of the predicted exceedances did not occur; the Probability of False Detection (POFD), which measures what fraction of the observed no-exceedances are incorrectly predicted; and the Critical Success Index (CSI), which measures how well both model exceedances and observed exceedances are predicted. These metrics facilitate the evaluation of the observed versus modelled $\mathrm{O}_{3}$ 15 concentrations and the exceedances/no-exceedances limit observed versus modelled (Eder et al., 2006).

\section{Results and discussion}

\subsection{General performance}

The CALIOPE air quality system reproduces the temporal variability of $\mathrm{O}_{3}$ properly, as in previous studies (Gonçalves et al., 2009; Pay et al., 2010; Baldasano et al., 2010). In Fig. 3 the average of all the observations (red line) is overall well represented by both the model results (dark blue) and the KF-output (bright blue) for max. 1-h and max. 8-h. The model results tend to underestimate the max. 1-h concentration mostly in winter/autumn months (January to April and September to December). It is a
GMDD

4, 343-384, 2011

\section{Ground-level ozone concentration over Spain}

V. Sicardi et al.

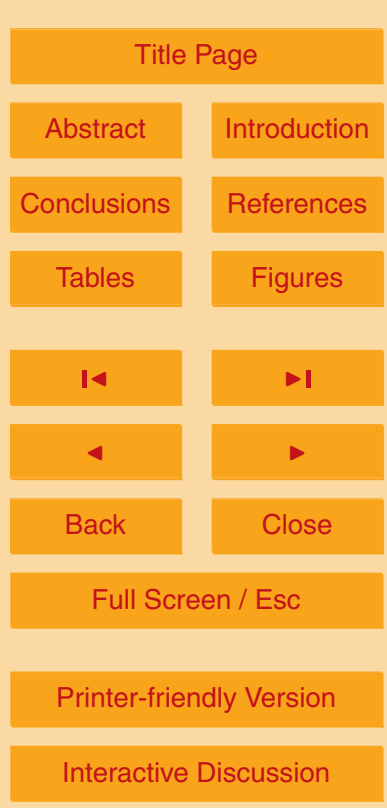


difficulties in the reproduction of the cross stratosphere-troposphere exchanges (Lam and Fu, 2009; Pay et al., 2010).

The results show that the $\mathrm{O}_{3}$ chemistry is well represented in summer, and the overall performance improves notably after applying the Kalman Filter. The overall $\mathrm{O}_{3}$ con5 centration shows improvement after the application of the post-processing (bright-blue line): the $\mathrm{O}_{3}$ concentration improves in reproducing the observed values even for those months in which the model results fail to reproduce the observed concentration. In the same figure are plotted the mean bias, for the model results (dark blue line with triangle) and for the KF-output (light blue line with triangle). It is notable that in the KF-output 10 the bias is reduced mostly for the winter months, while for the summer months the bias is already quite low due to the good representation of the summer $\mathrm{O}_{3}$ behaviour.

The averaged mean bias value for the max. 1-h is larger for the post-processed output: $-2.16 \mathrm{\mu g} \mathrm{m}^{-3}$ for the KF-output against $-1.27 \mathrm{\mu g} \mathrm{m}^{-3}$ for the model results. These values are the averages of the mean biases of all the stations considered, therefore if 15 the biases are extreme, they compensate mutually when averaged. On the contrary, in the KF-output the MB values are not so extremes and therefore the calculated average results larger. In the case of max. 8-h the MB improves notably after the Kalman Filter is applied (from $4.01 \mathrm{\mu g} \mathrm{m}^{-3}$ to $-0.99 \mathrm{\mu g} \mathrm{m}^{-3}$ ). All the calculated statistics are summarized in Table 2.

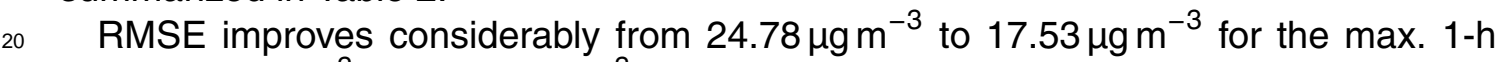
and $23.53 \mathrm{\mu g} \mathrm{m}^{-3}$ to $15.70 \mu \mathrm{g} \mathrm{m}^{-3}$ for the max. 8-h. A minor degree of improvement is observed for the correlation coefficient from $r=0.70$ to 0.77 for both the max. 1-h and 8-h. Minor improvement is observed in the Standard Deviation of the error $\left(\mathrm{Sd}_{\mathrm{er}}\right)$, which is reduced of about $20 \%$ in both the max. 1-h and 8-h. Taking into account the threshold limits established by the US-EPA (MNBE $\leq 15 \%$ and MNGE $\leq 35 \%$ ) we see that the model results would meet the US-EPA target for MNBE for the max. 1-h, but not for the max. 8-h. The MNBE varies from $10.29 \%$ (model results) to $2.40 \%$ (KFoutput) for the max. 1-h and from $23.21 \%$ (model results) to $4.7 \%$ (KF-output) for the max. 8-h. The MNGE of the model results for the max. $1-\mathrm{h}$ is $32.12 \%$ and decreases to

GMDD

4, 343-384, 2011

\section{Ground-level ozone concentration over Spain}

V. Sicardi et al.

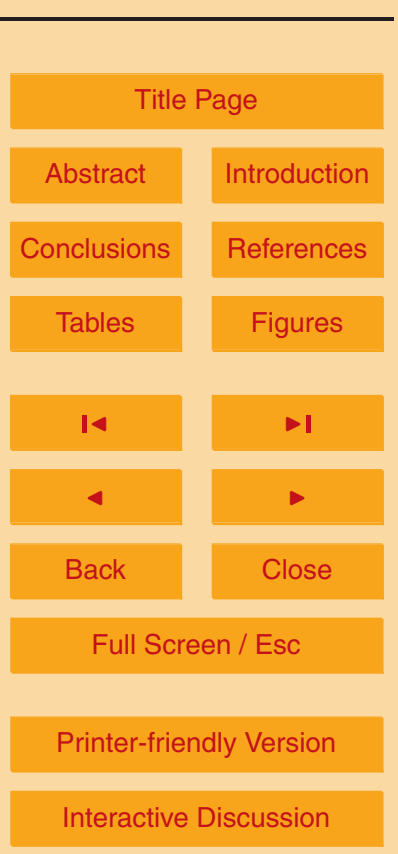


$19.60 \%$ after the application of the filter. The MNGE of the model results for the max. $8-\mathrm{h}$ is equal to $40.33 \%$ and therefore it would not meet the USA-EPA target. On the contrary, the US-EPA target would be met after the application of the KF, with a value of the MNGE equal to $21.50 \%$ (Table 2). The improvements in the statistical metrics are 5 easily visible when looking at their spatial distribution (Figs. 4 and 5). All the stations, independent of the type of station, show better statistical parameters for the KF- output. Generally speaking this finding is true for both the max. 1-h and max. 8-h.

We use Taylor diagrams (Taylor, 2001) to easily visualize the statistical differences between the model results and the KF-output. This allows us to gauge the relative skills 10 of different models by the means of the visualization in a single polar plot the RMSE, the correlation coefficient and the standard deviation for all the stations (Fig. 6). The standard deviation is not normalized to avoid masking the difference between station types. Almost all the stations for the model results (dark blue symbols) have a correlation coefficient in the range 0.6 to 0.7 , which becomes 0.7 to 0.9 after applying the

$15 \mathrm{KF}$ (light blue symbols). Also, the standard deviation improves for the KF-output: high correlation coefficient and low standard deviation indicates that the observed variability is well captured. These findings are valid both for the max. 1-h and max. 8-h.

Improvements by the application of the KF are much noticeable by looking at the scatter plot of models versus observations for all the stations over the whole year 20 (Fig. 7). The KF- output (Panel B Fig. 7) compared with the model results (Panel A Fig. 7) displays a better match with the observed distributions as reflected by the reduction of the scattered area. In the figure the exceedance limits and the values of the contingency table are added to visualize the categorical behaviour. Details are in the following section.

\subsection{Categorical performance}

We perform a categorical analysis of our results in order to highlight the ability of the modelling system to detect the $\mathrm{O}_{3}$ concentrations that exceed the air quality target

\section{GMDD}

4, 343-384, 2011

\section{Ground-level ozone concentration over Spain}

V. Sicardi et al.

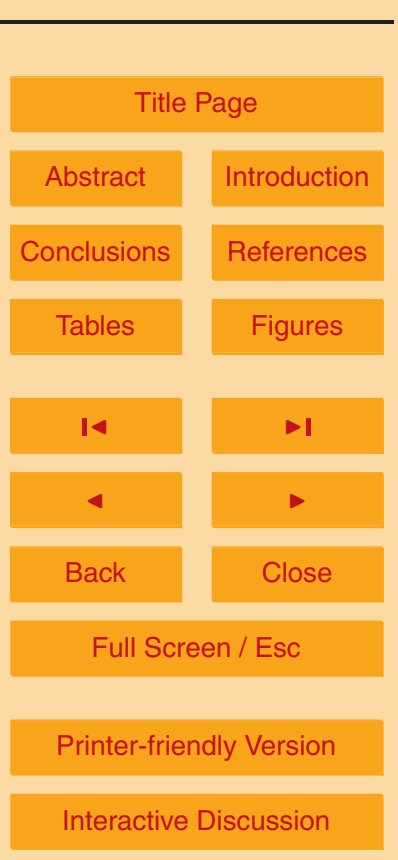


for $\mathrm{O}_{3}$ as established in the EU Directive 2008/50/EC. A visual evaluation of the model performance regarding the exceedance limit is provided in Fig. 7. The figure represents the categorical evaluation of the model results and KF-output, for the max. 1-h and max. 8-h for all the 82 stations. The letters on the plots represent the variable used 5 to formulate the categorical metrics, where a are the exceedances that did occur and were simulated by the model (hits); $b$ are the exceedances that did not occur but were simulated by the model (false alarm); $c$ are the exceedances that did occur but were not simulated by the model (misses), and $d$ are the exceedances that did not occur and were not simulated by the model (correct negatives). These variables, together 10 with some categorical metrics (Table 3), help to enlighten the improvements carried by the application of the Kalman Filter.

In Fig. 7 the higher the aggregation of points, the more the model simulation matches the observations. For the KF-output (Panel B Fig. 7) most of the points are grouped around the line, indicating better correspondence between the modelled concentrations 15 and the observed values. The number of hits (a in the Fig. 7) increases substantially after post-processing the data for both the max. 1-h and max. 8-h. On a total of 127 exceedances of the limit $180 \mathrm{\mu g} \mathrm{m}^{-3}$ for the max. 1-h, only 1 has been reproduced by the modelling system; while after the post-processing the number of hits increases to 21. For the max. 8-h, on a total of 2265 exceedances the numbers of hits simulated 20 is 703 for the model results and increases to 1085 after applying the post-processing. The exceedances simulated by the model that are actually not observed decrease (false alarms, b in Fig. 7) after the post-processing for the max. 8-h (from 1622 to 756), while for the max. 1-h it remains in the same order of magnitude. The exceedances that actually occur but the model does not simulate (misses, c in Fig. 7), improves as well 25 after the post-processing, both for the max. 1-h and max. 8-h exceedances (from 126 to 106 for the max. 1-h and from 1462 to 1080 for the max. 8-h). This variable, as the hits, is very different for the max. 1 -h and 8 -h and it is sensitive to the total exceedances/noexceedances. The no-exceedances that actually did not occur (correct negative, $\mathrm{d}$ in Fig. 7) are well represented by the model and do not improve after the application of

GMDD

4, 343-384, 2011

\section{Ground-level ozone concentration over Spain}

V. Sicardi et al.

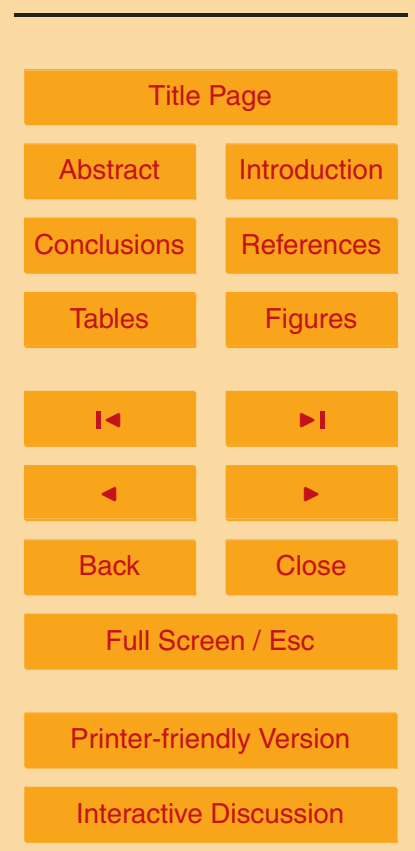

Interactive Discussion 
the post-processing for the max. 1-h. An improvement of about $4 \%$ is observed after the post-processing for the max. 8-h.

We must take into account that the categorical statistics depend on the number of exceedence or no-exceedances captured by the model; therefore caution is needed when 5 interpreted. In particular in cases as ours, in which the number of exceedances are few, we must have caution when analyzing the Accuracy $(A)$ (ideally 1 ) that measures the percentage of simulations that correctly reproduce an exceedance or no-exceedance. The Accuracy is already very high for the model results and no improvements are observed after the post-processing; this is due to the few exceedances observed, re10 spect to the total. The Bias, which ideally would be 1 and indicates if our hindcasts are over-predicted (false positive) or under-predicted (correct negative), improves after the post-processing. The max. 1-h for both the model results and the KF-output are slightly under-predicted $(B<1)$, while the max. 8-h for the model results is slightly over-predicted $(B>1)$, and for KF-output is under-predicted $(B<1)$. We attribute this 15 low improvement in the Bias after the post-processing to a poorer performance in detecting the exceedances in both the model results and the KF-output.

To evaluate how many times the model simulates the exceedances, which actually did not occur, the value of FAR (False Alarm Ratio) is used. The ideal value would be 0 and the application of the post-processing reduces of almost the half the value of the FAR for the max. 8-h. This finding indicates the ability of the post-processing to reduce the number of projected false alarms (from 1622 to 756). For the max. 1-h the false alarms $(b)$ detection does not improve after the post-processing (from 21 to 22 before and after the post-processing respectively), but nevertheless the FAR improves due to the improving of hits detections (a). The percentage of actual exceedances that are actually detected (Probability of Detection, POD) improves strongly after the KF post-processing for both the max. 1-h and max. 8-h, reaching an improvement of more than $100 \%$ in the case for the max. 1-h. This means that by the application of the KF the exceedances would be captured by the modelling system with significantly certainty. The Probability of False Detection (POFD), which indicates the probability

GMDD

4, 343-384, 2011

\section{Ground-level ozone concentration over Spain}

V. Sicardi et al.

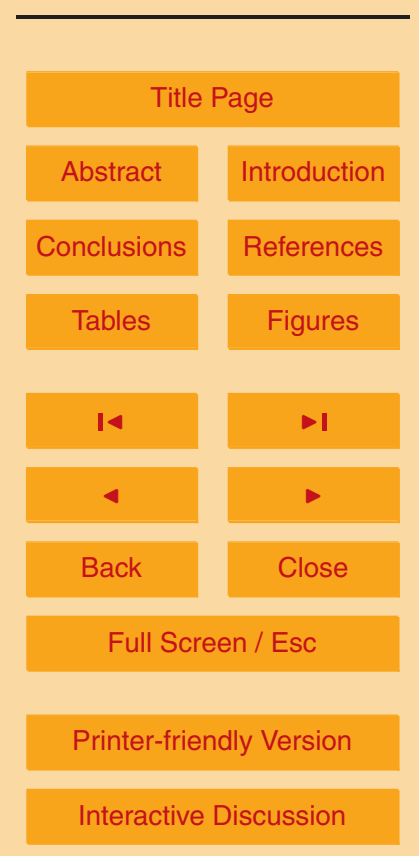

Interactive Discussion 
of false alarm, improves after post-processing the data. In this way the false alerts for the population would be reduced. Finally the Critical Success Index (CSI) indicates how well both the observed exceedances and the false exceedances are projected, the ideal value would be 1. For both the max. 1-h and the max. 8-h the application of 5 the post-processing improves this value. Unlike the POD and the FAR, the CSI takes into account both false alarms and missed events, and it is therefore a more balanced score.

\subsection{Daily cycle}

To detect common periodicities, a standard method of time-series analysis has been used: computing the Fourier transform and plotting the power density spectrum over the frequency. We compute the spectral analysis of the hourly data in order to catch the signal of characteristic periods as done in previous studies (Hies et al., 2000; Sebald et al., 2000; Marr et al., 2002). We use the periodogram method as estimate of the spectral density calculated in its simplest form: the squared amplitude in function of frequency (Alter, 1937). The time series is decomposed into spectral bands representing the different time scales: intra-day, diurnal, synoptic, seasonal and long term fluctuations. The highest amplitudes of a spectrum indicate the main periodicities of the underlying processes (Fig. 8). The periodogram in Fig. 8 reveals the ability of the modelling system to capture the variability associated with synoptic to long-term scales.

20 The annual cycle in the $\mathrm{O}_{3}$ time series is not visible in this periodogram because of the limited data range, since the length of the record should be 10 times as long as the longest significant period (Hies et al., 2000). The results show poor model ability in representing the observed daily and intra-day variability. The modelling system shows a tendency to underestimate the high frequency variability (intra-day and hour-to-hour variability), a feature which is corrected by the post-processing
further investigated by the temporal analysis of the daily cycle.

We compute the average daily cycle of observed and simulated hourly ozone concentrations for both the model results and the KF-output (Fig. 9). The box plot helps to
GMDD

4, 343-384, 2011

\section{Ground-level ozone concentration over Spain}

V. Sicardi et al.

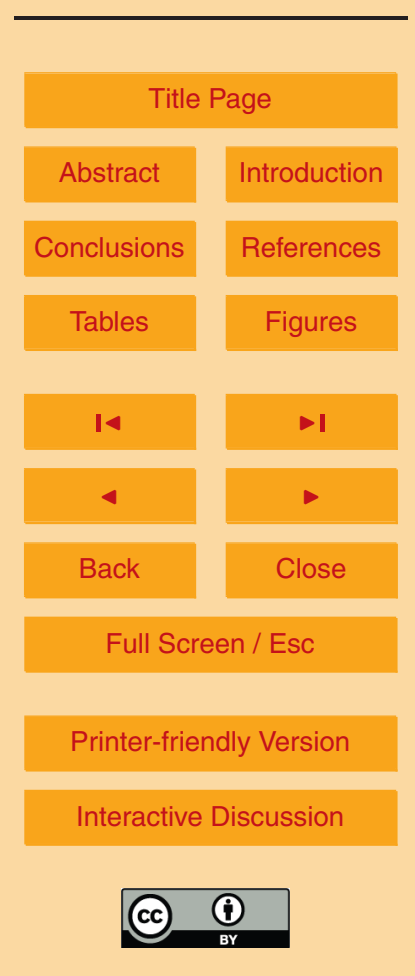


visualize the distribution, its central value, and spread of the represented values. In the figure are depicted the lower and upper quartiles, and the median. The mean is overplotted for completeness. The overall daily cycle is reproduced by the model results: maximum $\mathrm{O}_{3}$ values during day time and minimum during night. However, the model 5 results show poor performance when representing the daily cycle amplitude and the extreme values. In the model results the amplitude of the daily cycle is underestimated (dimension of the boxes in Fig. 9), both the night minimum and the daytime maximum are underestimated while the overall mean value (overlaying line on the boxes) is overestimated. The simulation improves after applying the Kalman Filter: the amplitude 10 of the cycle becomes well represented and the extreme values are better estimated (Fig. 9).

A known problem of the air quality models is to reproduce the night minimum. The possible explications of such behaviour are examined by several previous studies. It is probable that the model chemistry does not represent properly ozone nighttime's titra15 tion, therefore the model simulates a no production of $\mathrm{O}_{3}$, but omits the mechanism of $\mathrm{O}_{3}$ consumption. Possible causes of the observed mismatch are the bad representation of the nocturnal boundary layer or the emissions injection profile (Appel et al., 2007; van Loon et al., 2007; Vautard et al., 2007; Chemel et al., 2010).

\subsection{Model uncertainty}

20 The European Directive 2008/50/CE establishes that numerical models have to meet certain model quality, namely have a certain modelling uncertainty, to be considered suited for air quality assessment. The level of uncertainty associated with the air quality modelling is a crucial issue to take into account when evaluating an air quality performance.

25 We compute the model uncertainty, expressed as MRDE, before and after the Kalman Filter post-processing to verify any improvements (Table 4). In both cases the computed uncertainty is well within the limit established by the European Directive $2008 / 50 / C E$ that is $50 \%$. The uncertainty of the model is $20 \%$ and $22 \%$ for the max.
GMDD

4, 343-384, 2011

\section{Ground-level ozone concentration over Spain}

V. Sicardi et al.

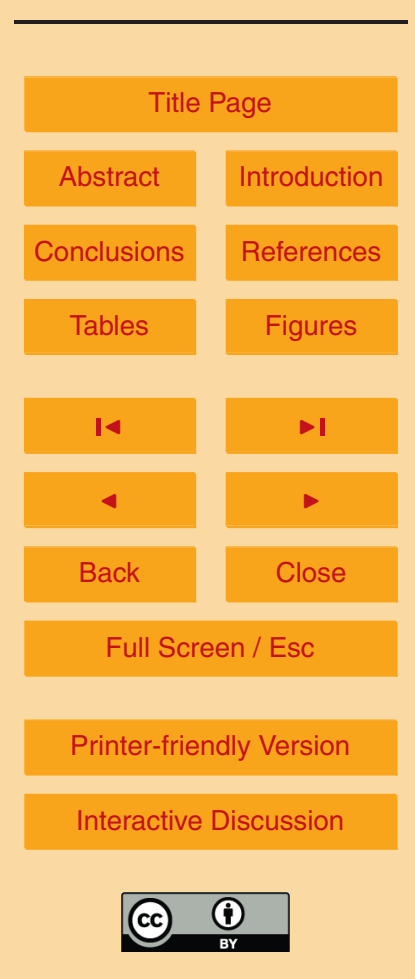


1-h and max. 8-h respectively, well under the uncertainty limit. This finding gives us confidence in the ability of CALIOPE system to represent the $\mathrm{O}_{3}$ concentrations, even before the post-processing. Nevertheless the improvement of the uncertainty in case of post-processed KF-output is considerably: the uncertainty is reduced from $19 \%$ to $57.5 \%$ for the max. 1-h and max. 8-h respectively.

The uncertainty, calculated in this way, indicates only whether the model is reliable or not. This definition of uncertainty must not be considered in terms of forecast interval, since it does not take into account the temporal information related to the formation/destruction of ozone. Furthermore, using this way of computing the uncertainty, 10 the number of the exceedances is independent of the sequence of the events. This approach is in contrast to a time-related process, in which the temporal correspondence is an important evaluation parameter, as it is in air quality studies.

\section{Conclusions}

We use the CALIOPE air quality modelling system to reproduce the daily maximum 15 of $\mathrm{O}_{3}$ ground level concentration over Spain for the full year 2004. We calculate the $\mathrm{O}_{3}$ daily maximum concentration at ground level over hourly data (max. 1-h) and over $8 \mathrm{~h}$ running average (max. 8-h). We use several statistical parameters in order to perform the model evaluation and check whether the modelling system meets the air quality EU Directive 2008/50/CE. We analyze the abilities of a post-processing technique, 20 namely the Kalman Filter, to improve the $\mathrm{O}_{3}$ simulation.

The results indicate on one hand, that the model results represent the $\mathrm{O}_{3}$ concentration with significant authenticity, but on the other hand, that the KF post-processing helps to achieve a more accurate match with the observations. By the analysis of the Correlation, Root Mean Square Error, Mean Bias, Standard Deviation of the Er-

ror, Mean Normalized Bias Error, and Mean Normalized Gross Error we observe a general improvement after the application of the Kalman Filter. Even the metrics associated with the categorical analysis display improvement after the KF post-process.
GMDD

4, 343-384, 2011

\section{Ground-level ozone concentration over Spain}

V. Sicardi et al.

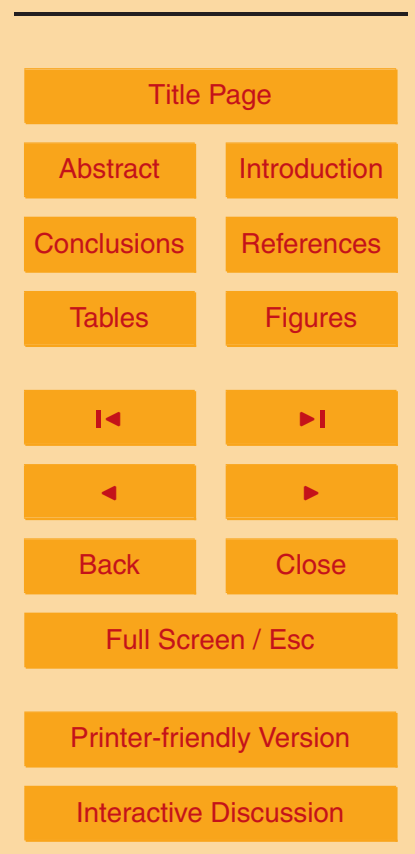


However, caution is needed when looking with those parameters at the categorical metrics. Accuracy, Bias and False Alarm are influenced by the number of exceedances and no-exceedances and, if analyzed alone, they are weak parameters for evaluating the model performance. Even though by the application of the Kalman Filter both the 5 simulated exceedances (hits) and no-exceedances (false alarm) are better simulated, the value of False Alarm Ratio (FAR) is still quite high (KF: 0.512 and 0.41 for max. 1-h and max. 8-h respectively, ideal is 0 ). For the max. 1-h on a total of 127 exceedances observed, only 1 is simulated by the model and the 21 after the post-process, which means that only the $16 \%$ of the exceedances are well captured by the model. For the 10 max. 8-h the percentage of hits increases to the $32 \%$. This finding, if on one hand indicates that KF post-processing leads to improvements in the $\mathrm{O}_{3}$ simulation, on the other hand, highlights that the number of the exceedances still remains underestimated. The Critical Success Index (CSI) and the Probability of Detection (POD) are more suitable to measure the model performance, since they take into account the misses of the 15 model. Categorical statistics improve after the application of the Kalman Filter.

The model results fall short in the prediction of the diurnal cycle, which is underestimated. Likely there are some crucial processes related to the resolution of the boundary layer, the emissions or the chemistry of $\mathrm{NO}_{-} \mathrm{O}_{3}$, missing in the modelling system. The $\mathrm{O}_{3}$ daily cycle presents higher agreement with observations when KF post-processing is applied, for both daily amplitude and extreme values.

The uncertainty calculated for the model results is within the limit proposed by the European Directive $2008 / 50 / C E$, which is $50 \%$ : the uncertainties are of $22 \%$ and $20 \%$ for max. 1-h and max. 8-h respectively. Notwithstanding for the KF-output the uncertainty is significantly reduced: $19 \%$ and $7.5 \%$ for max. 1 -h and max. 8 -h respectively.

In this study the Kalman Filter is applied only to discrete points (82 measurements stations), hence, further investigation is needed in order to extend the bias correction to the full domain and produce bias corrected spatial maps.
GMDD

4, 343-384, 2011

\section{Ground-level ozone concentration over Spain}

V. Sicardi et al.

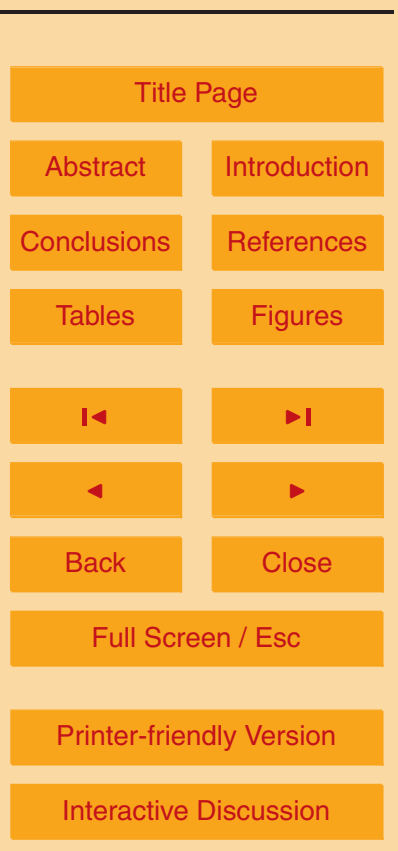


Acknowledgements. The authors wish to thank Luca Delle Monache and Ronald B. Stull for providing the Kalman Filter algorithm used in this study. All the computation has been done at the MareNostrum supercomputer hosted by the Barcelona Supercomputing Center-Centro Nacional de Supercomputación (BSC-CNS). This work is funded by the CALIOPE project of the 5 Spanish Ministry of the Environment (441/2006/3-12.1, A357/2007/2-12.1, 157/PC08/3-12.0).

\section{References}

Alter, D.: A simple form of periodogram, Ann. Mat. Stat., 8, 2, 121-126, 1937.

Appel, K. W., Bhave, P. V., Gilliland, A. B., Sarwar, G., and Roselle, S. J.: Evaluation of the community multiscale air quality (CMAQ) model version 4.5: Sensitivities impacting model performance; Part II-particulate matter, Atmos. Environ., 42, 6057-6066, doi:10.1016/j.atmosenv.2008.03.036, 2008.

Arévalo, G., Salvador, R., Gassó, S., Millán, M., and Baldasano, J. M.: Application of a highresolution emission model in Valencia Community (Spain), Air Pollution 2004, WIT Press, Rhodes, Greece, 31-40, 2004

Baldasano, J. M., Valera, E., and Jiménez, P.: Air Quality Data from Large Cities, Sci. Total Environ., 307, 1-3, 141-165, 2003.

Baldasano, J. M., Cremades, L., and Soriano, C.: Circulation of air pollutants over the Barcelona Geographical Area in summer, in: Proceedings of the Sixth European Symposium on Physico-Chemical Behaviour of Atmospheric Pollutants, Varese, Italy, 18-22 October 1993, Report EUR 15609/1, 474-479, 2004.

Baldasano, J. M., Jiménez-Guerrero, P., Jorba, O., Pérez, C., López, E., Üereca, P., Martín, F., Vivanco, M. G., Palomino, I., Querol, X., Pandolfi, M., and M. J., and Diéguez, J. J.: Caliope: an operational air quality forecasting system for the Iberian Peninsula, Balearic Islands and Canary Islands - first annual evaluation and ongoing developments, Adv. Sci. Res., 2, 89-98, $252008 a$.

Baldasano, J. M., Güereca, L. P., Lopez, E., Gassó, S., and Jiménez-Guerrero, P.: Development of a high-resolution ( $1 \mathrm{~km} \times 1 \mathrm{~km}, 1 \mathrm{~h}$ ) emission model for Spain: The High-Elective Resolution Modeling Emission System (HERMES), Atmos. Environ., 42(31), 7215-7233, 2008b.

Baldasano, J. M., Pay, M. T., Jorba, O., Piot, M., and Jiménez, P.: An annual assessment of air quality with the CALIOPE modeling system over Spain, Sci. Total Environ., accepted, 2010.

\section{GMDD}

4, 343-384, 2011

\section{Ground-level ozone concentration over Spain}

V. Sicardi et al.

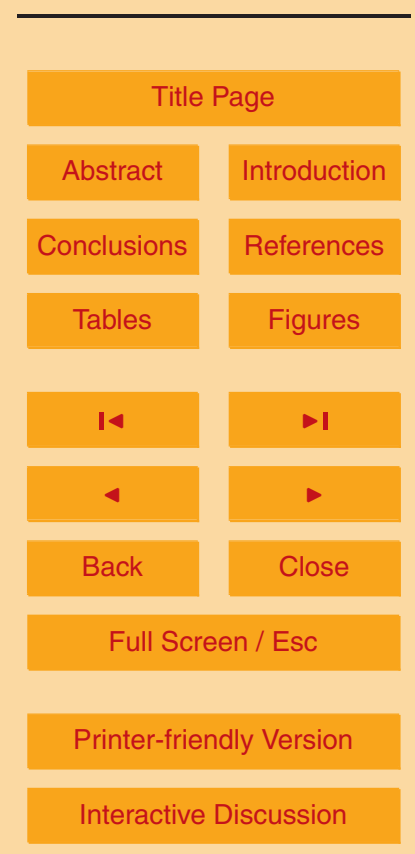


Binkowski, F. S.: Aerosols in models-3 CMAQ, in: Science Algorithms of the EPA Models3 Community Multiscale Air Quality (CMAQ), edited by: Byun, D. W. and Ching, J. K. S., Modeling System, EPA, 10-23, 1999.

Binkowski, F. S. and Roselle, S. J.: Models-3 Community Multiscale Air Quality (CMAQ) model aerosol component 1. Model description, J. Geophys. Res., 108(D6) 4183, doi:10.1029/2001JD001409, 2003.

Borrego, C., Tchepel, O., Costa, A. M., Amorim, J. H., and Miranda, A. I.: Emission and dispersion modeling of Lisbon air quality at local scale, Atmos. Environ., 37, 5197-5205, doi:10.1016/j.atmosenv.2003.09.004, 2003.

10 Borrego, C., Monteiro, A., Ferreira J., Miranda, A. I., Costa, A. M., Carvalho, A. C., and Lopes, M.: Procedures for estimation of modeling uncertainty in air quality assessment, Environ. Int., 34(5), 613-20, doi:10.1016/j.envint.2007.12.005, 2008.

Brauer M. and Brook, J. R.: Ozone personal exposures and health effects for selected groups residing in the Freser Valley, Atmos. Environ., 31(14), 2113-2121, 1997.

Byun, D. W. and Ching, J. K. S.: Science Algorithms of the EPA Models-3 Community Multiscale Air Quality (CMAQ) Modeling System. EPA/600/R-99/030, US EPA, National Exposure Research Laboratory, Research Triangle Park, NC, 1999.

Byun, D. W. and Schere, K. L.: Review of the governing equations, computational algorithms, and other components of the Models-3 Community Multiscale Air Quality (CMAQ) modeling system, Appl. Mech. Rev., 59, 51-77, 2006.

Carter, W. P. L.: Implementation of the SAPRC-99 Chemical Mechanism into the Models-3 Framework, Report to the United States Environmental Protection Agency, 29 January, available at: http://www.cert.ucr.edu/ carter/absts.htm\#s99mod3, 2000.

Chang, J. C. and Hanna, S. R.: Air quality model performance evaluation, Meteorol. Atmos. Phys., 87, 167-196, doi:10.1007/s00703-003-0070-7, 2004.

Chemel, C., Sokhi, R., Yu, Y., Hayman, G., Vincent, K., Dore, A. J., Tang, Y., Prain, H., and Fisher, B.: Evaluation of a CMAQ simulation at high resolution over the UK for the calendar year 2003, Atmos. Environ., 44, 24, 2927-2939, doi:10.1016/j.atmosenv.2010.03.029, 2010.

Cristofanelli, P. and Bonasoni, P.: Background Ozone in the southern Europe and Mediterranean area: Influence of the transport processes, Environ. Pollut., 157, 5, 1399-1406, doi:10.1016/j.envpol.2008.09.017, 2009.

Delle Monache, L., Nipen, T., Deng, X., Zhou, Y., and Stull, R.: Ozone ensemble forecasts: 2. A Kalman filter predictor bias correction, J. Geophys. Res., 111, D05308,

\section{Ground-level ozone concentration over Spain}

V. Sicardi et al.

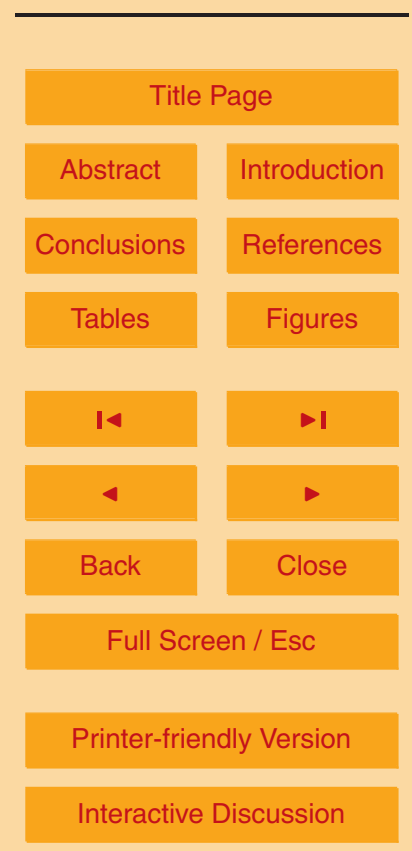

Interactive Discussion 
doi:10.1029/2005JD006311, 2006.

Delle Monache, L., Wilczak, J., Mckeen, S., Grell, G., Pagowski, M., Peckham, S., Stull, R., McHenry, J., and McQueen, J.: A Kalman-filter bias correction method applied to deterministic, ensemble averaged, and probabilistic forecasts of surface ozone, Tellus Ser. B, 60, $5 \quad$ 238-249, doi:10.1111/j.1600-0889.2007.00332.x, 2008.

Denby, B., Georgieva, E., Larssen, S., Guerreiro, C., Li, L., Douros, J., Moussiopoulos, N., Fragkou, L., Gauss, M., Olesen, H., Miranda, A. I., Dilara, P., Thunis, P., Sari, L., Rouil, L., Lükewille, A., Querol, X., Martin, F., Schaap, M., Van den Hout, D., Kobe, A., Silibello, C., Vincent, K., Stedman, J., Gonçalves, M., Pirovano, G., Volta, L., Van Pul, A., González Ortiz, A., Roberts P., and Oettl, D.: Guidance on the use of models for the European Air Quality Directive. A working document of the Forum for Air Quality Modeling in Europe FAIRMODE, Technical Report Version 6.1, edited by: B. Denby, 1-99, 2010.

Dennis, R., Fox, T., Fuentes, M., Gilliland, A., Hanna, S., Hogrefe, C., Irwin, J., Rao, S. T., Scheffe, R., Schere, K., Steyn, D., and Venkatram, D.: A framework for evaluating regional-scale numerical photochemical modeling systems, Environ. Fluid Mech., doi:10.1007/s10652-009-9163-2, 2010.

Eder, B., Kang, D., Mathur, R., Yu, S., and Schere, K.: An operational evaluation of the Eta-CMAQ air quality forecast model, Atmos. Environ., 40, 4894-4905, doi:10.1016/j.atmosenv.2005.12.062, 2006.

20 European Commission: Directive 2008/50/EC of the European Parliament and of the Council of 21 May 2008 on ambient air quality and cleaner air for Europe, Technical Report 2008/50/EC, L152, Off. J. Eur. Comm, 2008.

Finlayson-Pitts, B. J.: Atmospheric Chemistry, PNAS, 107(15), 6566-6567, 2010.

Flemming, J. and Stern, R.: Testing model accuracy measures according to the EU directivesexamples using the chemical transport model REM-CALGRID, Atmos. Environ., 41, 92069216, doi:10.1016/j.atmosenv.2007.07.050, 2007.

Folberth, G. A., Hauglustaine, D. A., Lathière, J., and Brocheton, F.: Interactive chemistry in the Laboratoire de Météorologie Dynamique general circulation model: model description and impact analysis of biogenic hydrocarbons on tropospheric chemistry, Atmos. Chem. Phys., 30 6, 2273-2319, doi:10.5194/acp-6-2273-2006, 2006.

Gangoiti, G., Millán, M. M., Salvador, R., and Mantilla, E.: Long-range transport and recirculation of pollutants in the western Mediterranean during the project Regional Cycles of Air Pollution in the West-Central Mediterranean Area, Atmos. Environ., 35, 6267-6276,

GMDD

4, 343-384, 2011

\section{Ground-level ozone concentration over Spain}

V. Sicardi et al.

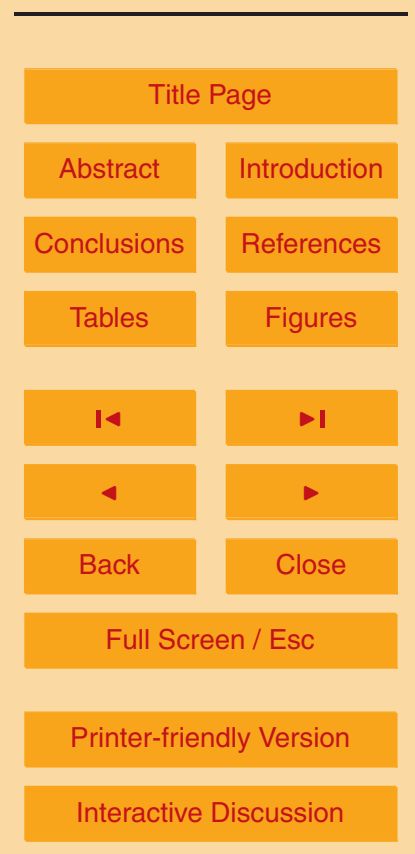

Interactive Discussion 
2001.

Garber, W., Colosio, J., Grittner, S., Larssen, S., Rasse, D., Schneider, J., and Housiau, M.: Guidance on the Annexes to Decision 97/101/EC on Exchange of Information as revised by Decision 2001/752/EC, Technical Report, European Commission, DG Environment 1-71, 52002.

Gerasopoulos, E., Kouvarakis, G., Vrekoussis, M., Kanakidou, M., and Mihalopoulos, N.: Ozone variability in the marine boundary layer of the eastern Mediterranean based on 7year observations, J. Geophys. Res., 110, D15309, doi:10.1029/2005JD005991, 2005.

Gery, M., Whitten, G., Killus, J., and Dodge, M.: A Photochemical Kinetics Mechanism for 10 Urban and Regional Scale Computer Modeling, J. Geophys. Res., 94(D10), 12925-12956, 1989.

Gonçalves, M., Jiménez-Guerrero, P., and Baldasano, J. M.: Contribution of atmospheric processes affecting the dynamics of air pollution in South-Western Europe during a typical summertime photochemical episode, Atmos. Chem. Phys., 9, 849-864, doi:10.5194/acp-9-849$15 \quad 2009,2009$.

Guenther, A. B., Hewitt, C. N., Erickson, D., Fall, R., Geron, C., Graedel, T., Harley, P., Klinger, L., Lerdau, M., McKay, W. A., Pierce, T., Scholes, B., Steinbrecher, R., Tallamraju, R., Taylor, J., and Zimmerman, P.: A global model of natural volatile organic compound emissions, J. Geophys. Res., 100, 8873-8892, 1995.

20 Hauglustaine, D. A, Hourdin, F., Jourdain, L., Filiberti, M. A., Walters, S., Lamarque, J. F., and Holland, E. A.: Interactive chemistry in the Laboratoire de Meteorologie Dynamique general circulation model: Description and background tropospheric chemistry evaluation, J. Geophys. Res., 109, 1-44, 2004.

Hies, T., Treffeisen, R., Sebald, L., and Reimer, E.: Spectral analysis of air pollutants. Part 1: elemental carbon time series, Atmos. Environ., 34, 21, 3495-3502, 2000.

Janjic, Z. I.: The step-mountain ETA coordinate model: Further developments of the convection, viscous sublayer and turbulence closure schemes, Mon. Weather Rev., 122, 927-945, 1994.

Jiménez, P. and Baldasano, J. M.: Ozone response to precursor controls in very complex terrains: Use of photochemical indicators to assess $\mathrm{O}_{3}-\mathrm{NO}_{\mathrm{x}}-\mathrm{VOC}$ sensitivity in the northeastern

30 Iberian Peninsula, J. Geophys. Res., 109, D20309, doi:10.1029/2004JD004985, 2004.

Jiménez, P., Parra, R., Gassó, S., and Baldasano, J. M.: Modeling the ozone weekend effect in very complex terrains: a case study in the northeastern Iberian Peninsula, Atmos. Environ., 39, 429-444, 2005a.

\section{Ground-level ozone concentration over Spain}

V. Sicardi et al.

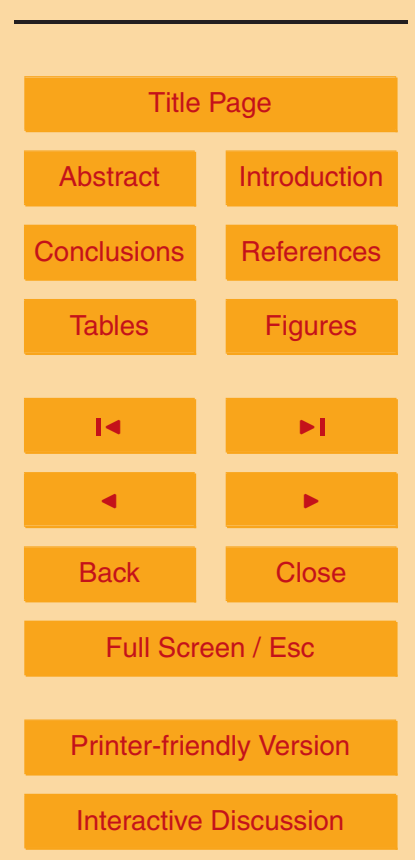

Interactive Discussion 
Jiménez, P., Jorba, O., Parra, R., and Baldasano, J. M.: Influence of high-model grid resolution on photochemical modeling in very complex terrains, Int. J. Environ. Pollut., 24, 180-200, 2005b.

Jiménez, P., Lelieveld, J., and Baldasano, J. M.: Multi-scale modeling of air pollutants Dy5 namics in the North-Western Mediterranean Basin during a typical summertime episode, J. Geophys. Res., 111, D18306, doi:10.1029/2005JD006516, 2006.

Jiménez, P., Jorba, O., Baldasano, J. M., and Gassó, S.: The Use of a Modeling System as a Tool for Air Quality Management: Annual High-Resolution Simulations and Evaluation, Sci. Tot. Env., 390, 323-340. doi:10.1016/j.scitotenv.2007.10.025, 2008.

10 Kalman, R. E.: A new approach to linear filtering and prediction problems, J. Basic Eng., 82, 35-45, 1960.

Kang, D., Eder, B. K., Stein, A. F., Grell, G. A., Peckham, S. E., and McHenry, J.: The New England air quality forecasting pilot program: Development of an evaluation protocol and performance benchmark, J. Air Waste Manage. Assoc., 55, 1782-1796, 2005

15 Kang, D., Mathur, R., Rao, S. T., and Yu, S.: Bias adjustment techniques for improving ozone air quality forecasts, J. Geophys. Res., 113, D23308, doi:10.1029/2008JD010151, 2008.

Kang, D., Mathur, R., and Trivikrama Rao, S.: Assessment of bias-adjusted $\mathrm{PM}_{2} .5$ air quality forecasts over the continental United States during 2007, Geosci. Model Dev., 3, 309-320, doi:10.5194/gmd-3-309-2010, 2010.

20 Lam, Y. F. and Fu, J. S.: A novel downscaling technique for the linkage of global and regional air quality modeling, Atmos. Chem. Phys., 9, 9169-9185, doi:10.5194/acp-9-9169-2009, 2009.

Marr, L. C. and Harley, R. A.: Spectral analysis of weekday-weekend differences in ambient ozone, nitrogen oxide, and non-methane hydrocarbon time series in California, Atmos. Environ., 36, 14, 2327-2335, doi:10.1016/S1352-2310(02)00188-7, 2002.

Michalakes, J., Dudhia, J., Gill, D., Henderson, T., Klemp, J., Skamarock, W., and Wang, W.: The weather research and forecast model, in: Software architecture and performance, edited by: Mozdzynski, E. G., Proceeding of the Eleventh ECMWF Workshop on the Use of High Performance Computing in Meteorology, 2529, Reading, UK, 117-124, 2004.

Millán, M., Salvador, R., and Mantilla, E.: Photooxidant dynamics in the Mediterranean basin in 30 summer: Results from European research projects, J. Geophys. Res., 102(D7), 8811-8823, 1997.

Millán, M., Sanz, M. J., Salvador, R., and Mantilla, E.: Atmospheric dynamics and ozone cycles related to nitrogen deposition in the western Mediterranean, Environ. Pollut., 118(2), 167-86,

\section{GMDD}

4, 343-384, 2011

\section{Ground-level ozone concentration over Spain}

V. Sicardi et al.

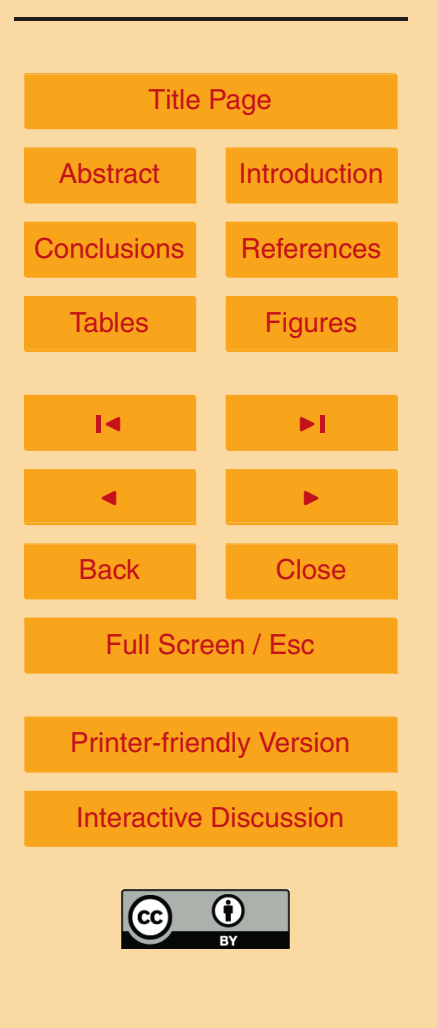


2002.

Nenes, A., Pandis, S. N., and Pilinis, C.: SORROPIA: A New Thermodynamic Equilibrium Model for Multiphase Multicomponent Inorganic Aerosols, Aquat. Geochem., 4, 123-152, 1998.

5 Nickovic, S., Kallos, G., Papadopoulos, A., and Kakaliagou, O.: model for prediction of desert dust cycle in the atmosphere, J Geophys. Res., 106(D16), 18113-18129, doi:10.1029/2000JD900794, 2001.

Parra, R., Gassó, S., and Baldasano, J. M.: Estimating the biogenic emissions of non-methane volatile organic compounds from the North Western Mediterranean vegetation of Catalonia,

10 Spain, Sci. Tot.Env., 29, 241-259, 2004.

Parra, R., Jiménez, P., and Baldasano, J. M.: Development of the high spatial resolution EMICAT2000 emission model for air pollutants from the north-eastern Iberian Peninsula (Catalonia, Spain), Environ. Pollut, 140, 200-219, 2006.

Pay, M. T., Piot, M., Jorba, O., Gassó, S., Gonçalves, M., Basart, S., Dabdub, D., Jiménez, P., 15 and Baldasano, J. M.: A full year evaluation of the CALIOPE-EU air quality modeling system over Europe for 2004, Atmos. Environ., 44, 3322-3342 doi:10.1016/j.atmosenv.2010.05.040, 2010.

Pérez, C., Nickovic, S., Baldasano, J. M., Sicard, M., Rocadenbosch, F., and Cachorro, V. E.: A long Saharan dust event over the western Mediterranean: Lidar, sun photometer observations, and regional dust modeling, J. Geophys. Res., 111, D15214, doi:10.1029/2005JD006579, 2006a.

Pérez, C., Nickovic, S., Pejanovic, G., Baldasano, J. M., and Ozsoy, E.: Interactive dustradiation modeling: A step to improve weather forecasts, J. Geophys. Res., 111, D16206, doi:10.1029/2005JD006717, 2006b.

25 Proyecto De Real Decreto Relativo A La Mejora De La Calidad Del Aire Ministerio De Medio Ambiente: Área de Calidad del Aire Subdirección General de Calidad del Aire y Medio Ambiente Industrial Ministerio de Medio Ambiente y Medio Rural y Marino, 2010.

Sebald, L., Treffeisen, R., Reimer, E., and Hies, T.: Spectral analysis of air pollutants. Part 2: ozone time series, Atmos. Environ., 34, 21, 3503-3509, 2000.

30 Skamarock, W. C., Klemp, J. B., Dudhia, J., Gill, D. O., Barker, D. M., Wang, W., and Powers, J. G.,: A Description of the Advanced Research WRF Version 2 NCAR Tech Notes-468, 2005.

Skamarock, W. C. and Klemp, J. B.: A time-split nonhydrostatic atmospheric model for weather research and forecasting applications, J. Comput. Phys., 227(7), 3465-3485,

GMDD

4, 343-384, 2011

\section{Ground-level ozone concentration over Spain}

V. Sicardi et al.

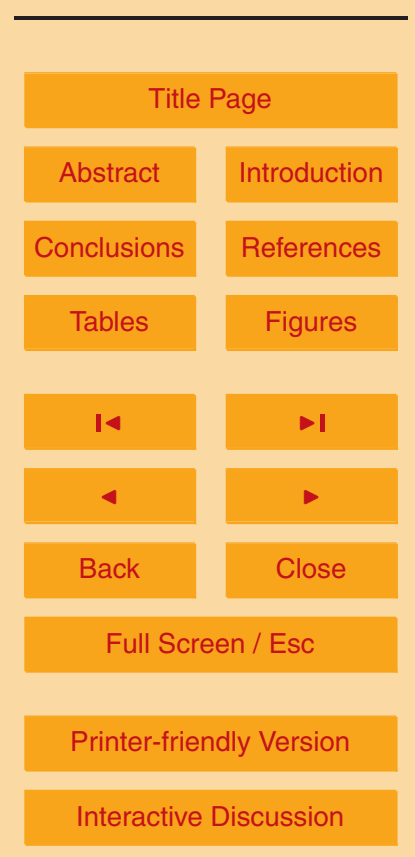

Interactive Discussion 
doi:10.1016/j.jcp.2007.01.037, 2008.

Staudt, M., Bertin, N., Frenzel, B., and Seufert, G.: Seasonal variations in amount and composition of monoterpenes emitted by young Pinus pinea trees - implications for emission modeling, J. Atmos. Chem., 35, 77-99, 2000.

5 Steinbrecher, R., Smiatek, G., Köble, R., Seufert, G., Thelokec, J., Hauff, K., Ciccioli, P., Vautard, R., and Curci, G.: Intra- and inter-annual variability of VOC emissions from natural and semi-natural vegetation in Europe and neighbouring countries, Atmos. Environ., 43, 13801391, 2009.

Taylor, K. E.: Summarizing multiple aspects of model performance in a single diagram, J. 10 Geophys. Res., 106(D7), 7183-7192, 2001.

US-EPA: Guideline for regulatory application of the urban airshed model, Technical Report, EPA-450/4-91-013, US Environmental Protection Agency, Office of Air Quality Planning and Standards: Research Triangle Park, NC, 1991.

US-EPA: AP-42, 5. Edition, Volume 1, Chapter 13, Section 13.2.1. Miscellaneous sources, 15 Technical Report, US Environmental Protection Agency, 1997.

US-EPA: AP-42, 5. Edition, Volume VI, Chapter 13, Section 13.2.1. Paved Roads. Technical Report. Guidance on the Use of Models and Other Analyses for Demonstrating Attainment of Air Quality Goals for Ozone, PM2.5, and Regional Haze. Technical Report. EPA-454/B07-002, US Environmental Protection Agency, Office of Air Quality Planning and Standards:

20 Research Triangle Park, NC, 2007.

US-EPA: Guidance on the Development, Evaluation, and Application of Environmental models, Office of the Science Advisor, Council for Regulatory Environmental Modeling EPA/100/K09/003, 1-99, 2009.

van Loon, M., Vautard, R., Schaap, M., Bergstrom, R., Bessagnet, B., Brandt, J., Builtjes, P., Christensen, J., Cuvelier, C., and Graff, A.: Evaluation of long-term ozone simulations from seven regional air quality models and their ensemble, Atmos. Environ., 41, 2083-2097, doi:10.1016/j.atmosenv.2006.10.073, 2007.

Vautard, R., Builtjes, P., Thunis, P., Cuvelier, C., Bedogni, M., Bessagnet, B., Honoré, C., Moussiopoulos, N., Pirovano, G., and Schaap, M.: Evaluation and intercomparison of Ozone and PM10 simulations by several chemistry transport models over four European cities within the CityDelta project, Atmos. Environ., 41, 173-188, doi:10.1016/j.atmosenv.2006.07.039, 2007.

West, J., Szopa, S., and Hauglustaine, D.: Human mortality effects of future concentrations

\section{GMDD}

4, 343-384, 2011

\section{Ground-level ozone concentration over Spain}

V. Sicardi et al.

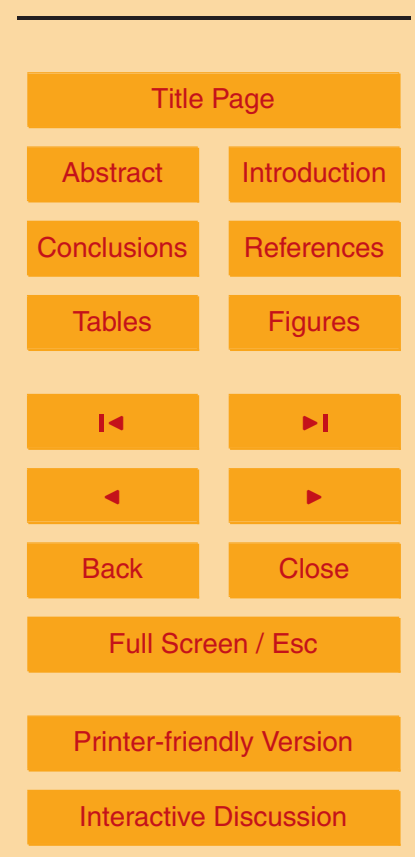


of tropospheric Ozone, C. R., Geoscience, 339, 775-783, doi:10.1016/j.crte.2007.08.005, 2007.

WHO: Health risks of ozone from long-range transboundary air pollution, World Health Organization, 111 pp., 2008.

\section{GMDD}

4, 343-384, 2011

\section{Ground-level ozone concentration over Spain}

V. Sicardi et al.

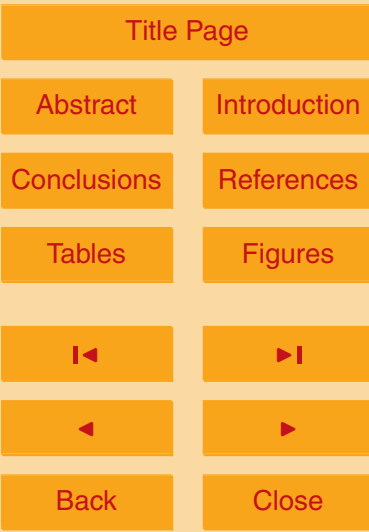

Full Screen / Esc

Printer-friendly Version

Interactive Discussion 


\section{GMDD}

4, 343-384, 2011

\section{Ground-level ozone} concentration over Spain

V. Sicardi et al.

Table 1. Error ratio values for bias-adjusted Root Mean Square Error and Correlation of ozone by seasons, for the year 2004 at the 82 RedESP stations.

\begin{tabular}{cc}
\hline SEASON & ERROR RATIO \\
\hline Winter & 0.40 \\
Spring & 0.20 \\
Summer & 0.15 \\
Autumn & 0.60 \\
\hline
\end{tabular}

Title Page

Abstract

Introduction

Conclusions

References

Tables

Figures

14

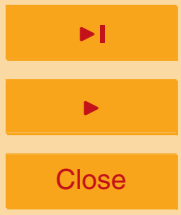

Back

Close

Full Screen / Esc

Printer-friendly Version

Interactive Discussion 


\section{GMDD}

4, 343-384, 2011

\section{Ground-level ozone concentration over Spain}

Table 2. Statistical comparison between model results and KF-output. The statistics are for the max. 1-h and max. 8-h for the whole domain, for the year 2004. MB and RMSE are expressed in unit of $\mathrm{O}_{3}$ concentration $\left(\mathrm{\mu g} \mathrm{m}^{-3}\right)$. All the statistics were determined based on hourly data for individual stations and then averaged.

\begin{tabular}{lcrrrr}
\hline \multirow{2}{*}{ Statistics } & \multicolumn{2}{c}{ Max. 1-h } & & \multicolumn{2}{c}{ Max. 8-h } \\
\cline { 2 - 3 } \cline { 6 - 6 } & Model & KF & & Model & KF \\
\hline COR & 0.70 & 0.77 & & 0.70 & 0.77 \\
RMSE & 24.78 & 17.53 & & 23.53 & 15.70 \\
MB & -1.27 & -2.16 & & 4.01 & -0.99 \\
SDer & 21.76 & 17.30 & & 20.44 & 15.62 \\
MNBE (\%) & 10.29 & 2.40 & & 23.21 & 4.70 \\
MNGE (\%) & 32.12 & 19.61 & & 40.33 & 21.50 \\
\hline
\end{tabular}

Title Page

Abstract

Introduction

Conclusions

References

Tables

Figures

14

4

Back

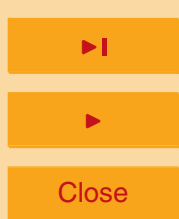

Full Screen / Esc

Printer-friendly Version

Interactive Discussion 


\section{GMDD}

4, 343-384, 2011

Table 3. Categorical Statistics for the model results and the KF-output over the max. 1-h and max. 8-h. All the statistics are calculated for the hourly data of the 82 stations, for all the 2004 . The perfect score is reported in parentheses. POD is the Probability of Detection, FAR is the False Alarm Ratio, POFD is the Probability of False Detection, CSI is the Critical Success Index, $A$ is the Accuracy, and B is the Bias. Refer to the text for the interpretation of these parameters.

\begin{tabular}{lccccc}
\hline Statistics (perfect score) & \multicolumn{2}{c}{ Max. 1-h } & & \multicolumn{2}{c}{ Max. 8-h } \\
\cline { 2 - 3 } \cline { 5 - 6 } & Model results & KF-output & & Model results & KF-output \\
\hline$a$ (hits) & 1 & 21 & & 703 & 1085 \\
$b$ (false alarm) & 21 & 22 & & 1622 & 756 \\
$c$ (misses) & 126 & 106 & & 1462 & 1080 \\
$d$ (correct negative) & 27822 & 27821 & & 23874 & 24740 \\
POD (1) & 0.008 & 0.165 & & 0.325 & 0.501 \\
FAR (0) & 0.955 & 0.512 & & 0.698 & 0.41 \\
POFD (0) & 0.001 & 0.001 & & 0.064 & 0.030 \\
CSI (1) & 0.007 & 0.141 & & 0.186 & 0.371 \\
$A(1)$ & 0.995 & 0.996 & & 0.889 & 0.934 \\
BIAS (1) & 0.173 & 0.339 & & 1.074 & 0.850
\end{tabular}

\section{Ground-level ozone concentration over Spain}

V. Sicardi et al.

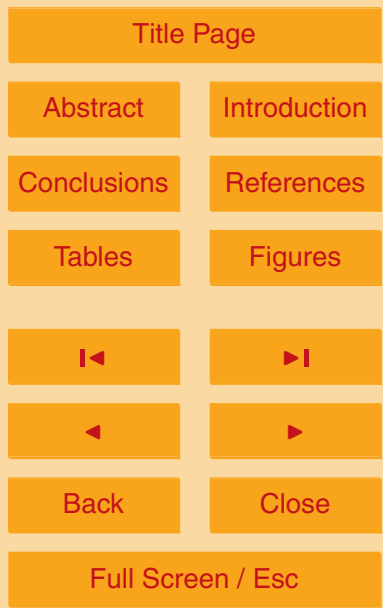

Printer-friendly Version

Interactive Discussion 


\section{GMDD}

4, 343-384, 2011

\section{Ground-level ozone concentration over Spain}

V. Sicardi et al.

Table 4. Uncertainty estimated according to the EU Directive 2008/50/CE for the model results and the KF-output over the max. 1-h and the max. 8-h.

\begin{tabular}{|c|c|c|c|}
\hline & \multicolumn{2}{|c|}{ Uncertainty (\%) } & 2008/50/CE \\
\hline & Model results & KF-output & \\
\hline Max. 1-h & $22 \%$ & $19 \%$ & \\
\hline Max. 8-h & $20 \%$ & $7.5 \%$ & $50 \%$ \\
\hline
\end{tabular}




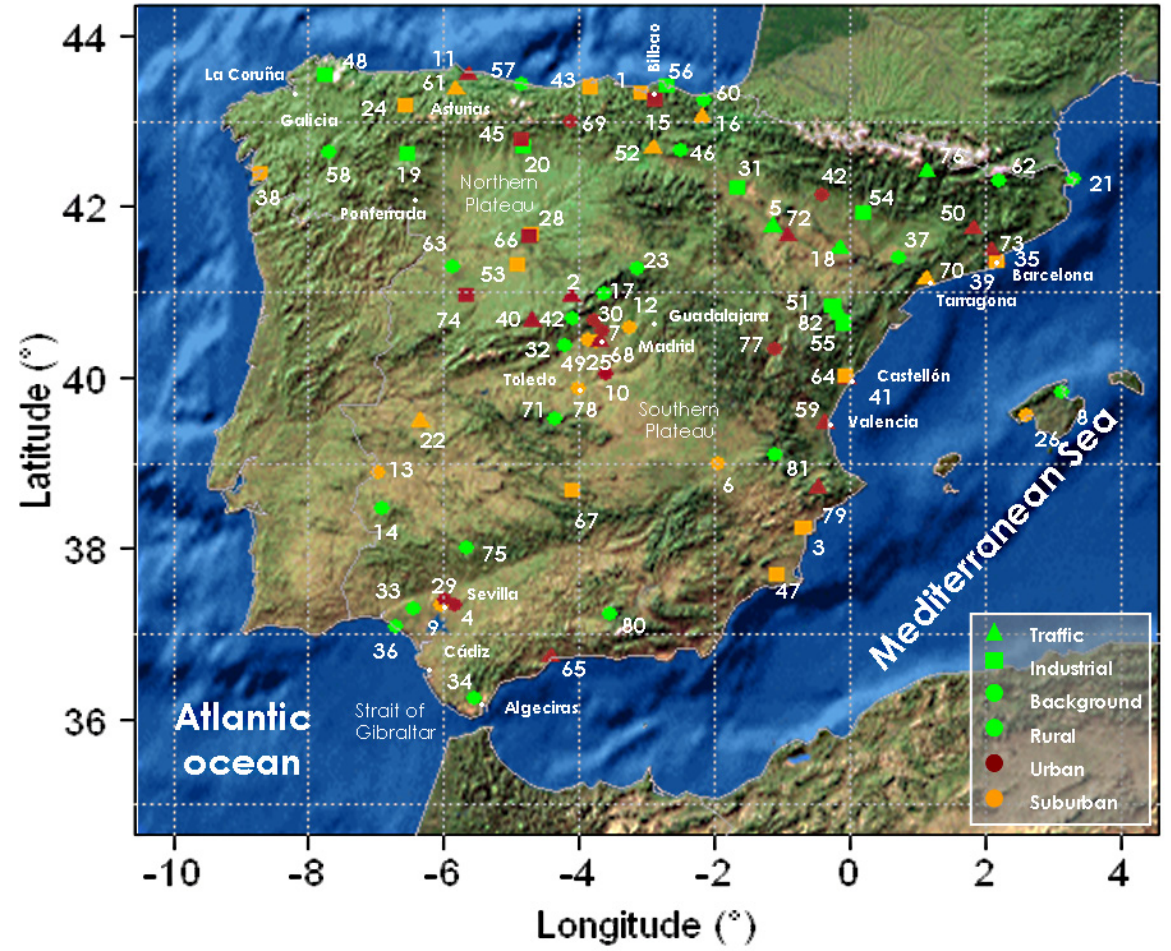

Fig. 1. RedESP stations network measuring ozone concentration in Spain. Different types of stations (U: Urban; S: Suburban; R: Rural; B: Background; I: Industrial; and T: Traffic) are represented by symbols and color codes.
GMDD

4, 343-384, 2011

Ground-level ozone concentration over Spain

V. Sicardi et al.

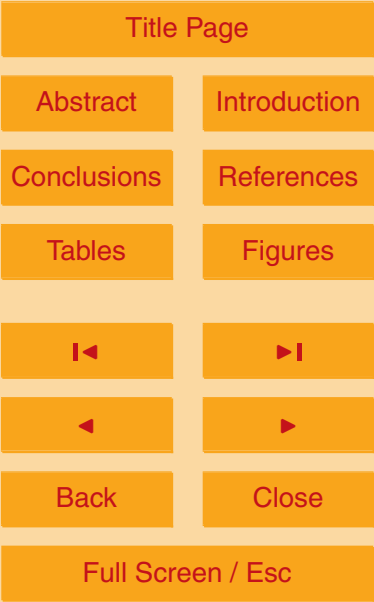

Printer-friendly Version

Interactive Discussion 

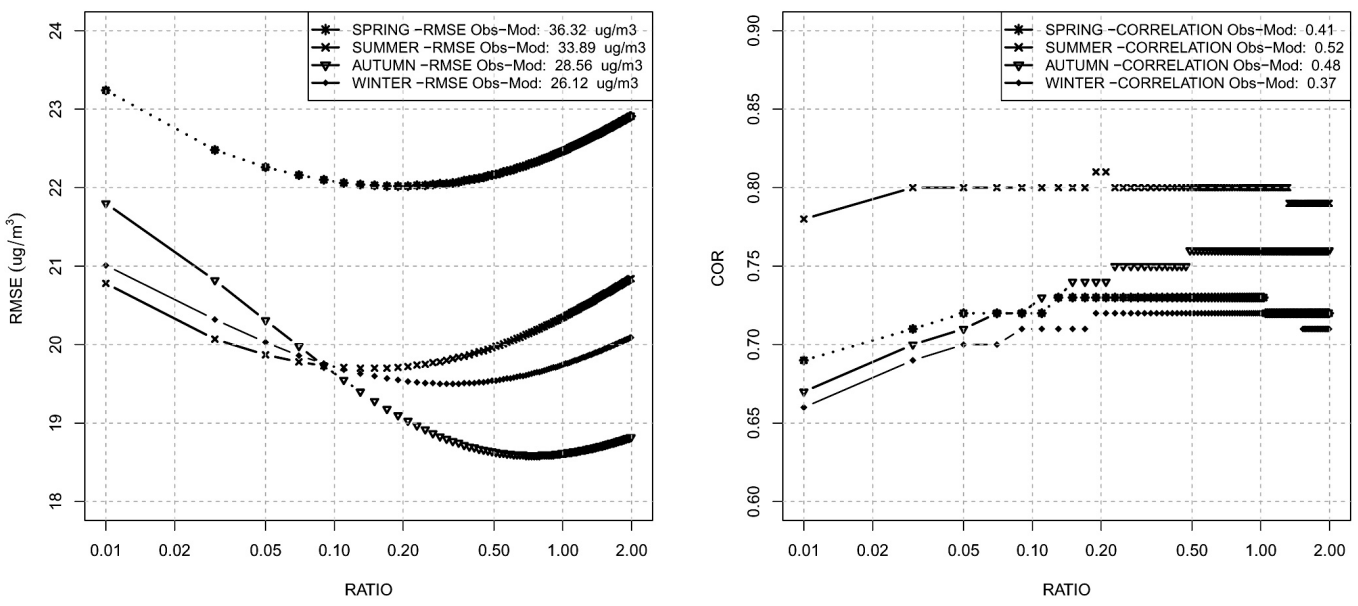

\section{GMDD}

4, 343-384, 2011

\section{Ground-level ozone concentration over Spain}

V. Sicardi et al.

Fig. 2. Seasonal ratio sensitivity for the hourly $\mathrm{O}_{3}$ concentrations over the 82 RedESP stations. Left Panel: Root Mean Square Error and Right Panel: Correlation. Values are computed with the ratio raging from 0.01 to 2 , plotted on logarithmic scale. Perfect RMSE would be 0 , and perfect correlation coefficient 1 . On the plots are reported RMSE and COR before the application of the Kalman Filter.

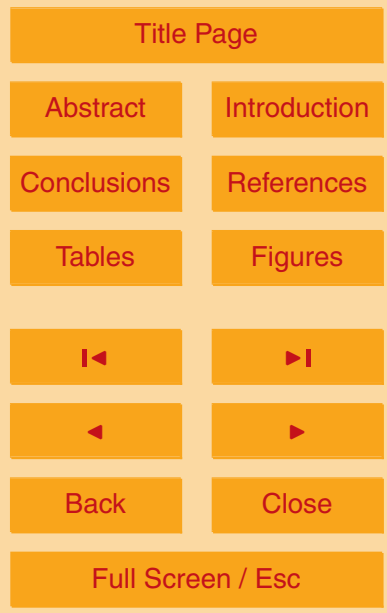

Printer-friendly Version

Interactive Discussion 


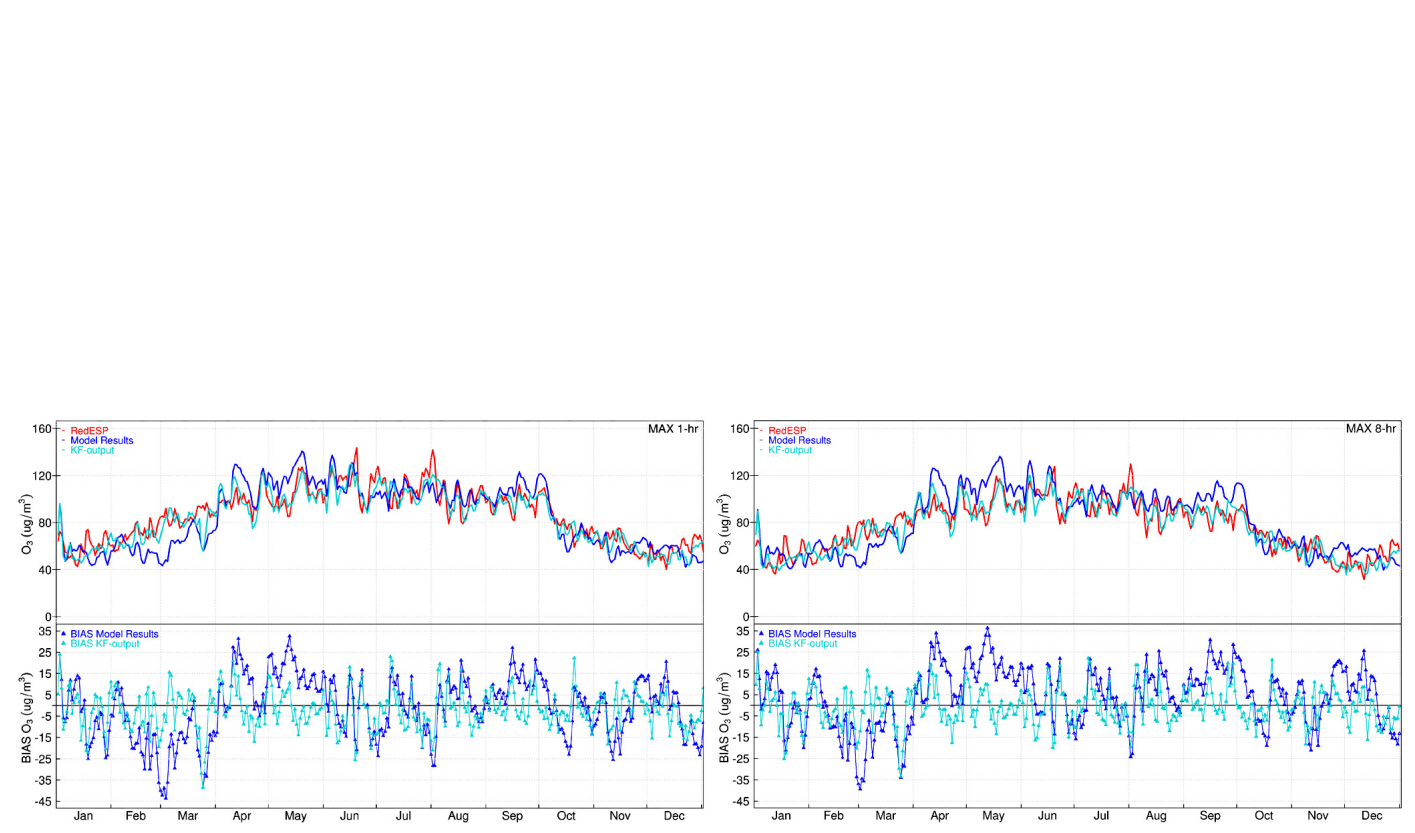

GMDD

4, 343-384, 2011

\section{Ground-level ozone concentration over Spain}

V. Sicardi et al.

Fig. 3. Time series of the max. 1-h ((left panel) and max. 8-h (right panel) ground level

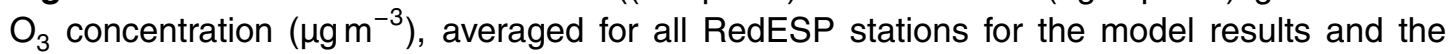
KF-output, for the year 2004. The plot of the biases $\left(\mu \mathrm{g} \mathrm{m}^{-3}\right)$ is also included. 

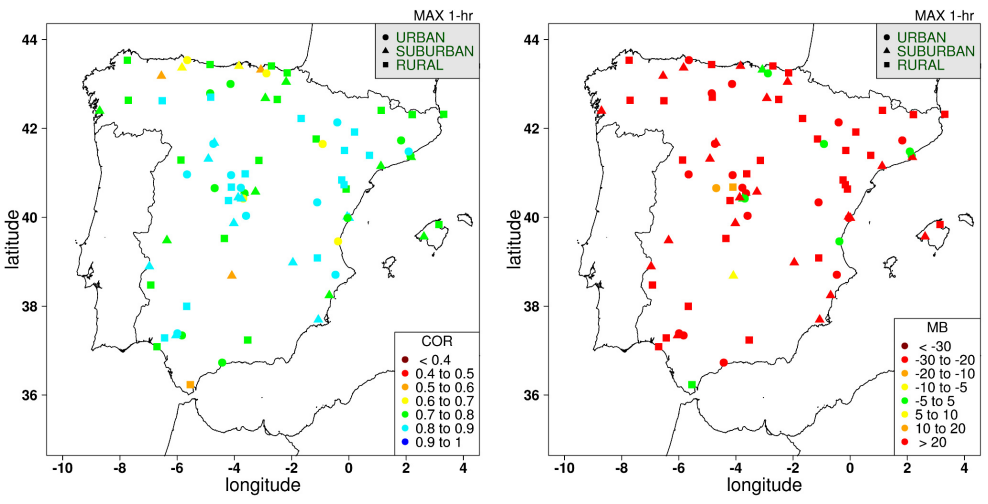

\section{GMDD}

4, 343-384, 2011

\section{Ground-level ozone concentration over Spain}
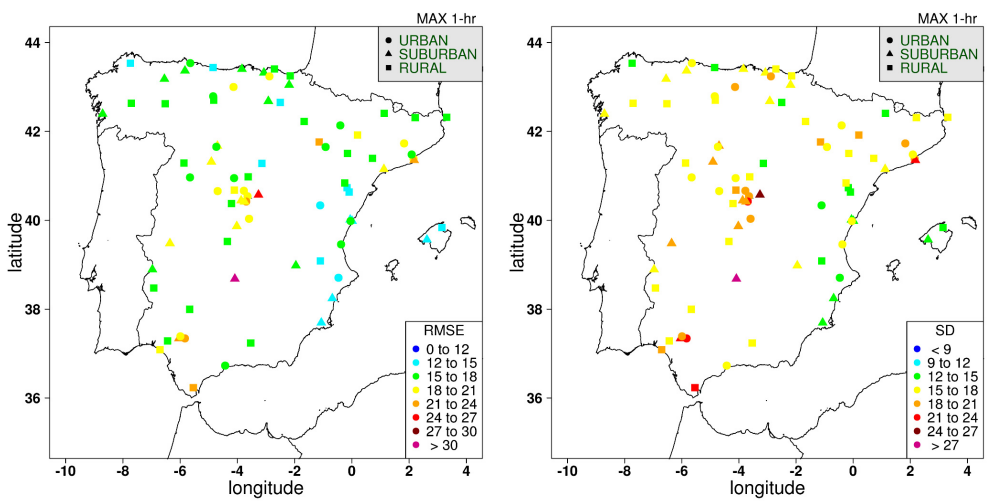

Title Page

Abstract

Introduction

V. Sicardi et al.

Conclusions

References

Tables

Figures

14

>I

4

Back

Close

Full Screen / Esc

Fig. 4. Spatial distribution of correlation (COR, ideal value would be 1), Mean Bias (MB, $\mu \mathrm{g} \mathrm{m}^{-3}$ ), Root Mean Square Error (RMSE, $\mu \mathrm{g} \mathrm{m}^{-3}$ ) and Standard Deviation of the error $\left(\mathrm{SD}_{\mathrm{er}}\right)$ for the max. 1-h, for all the RedESP stations, averaged over the year 2004. The air quality monitoring stations are represented according to their type: urban (dots), suburban (triangle), and rural (square). 

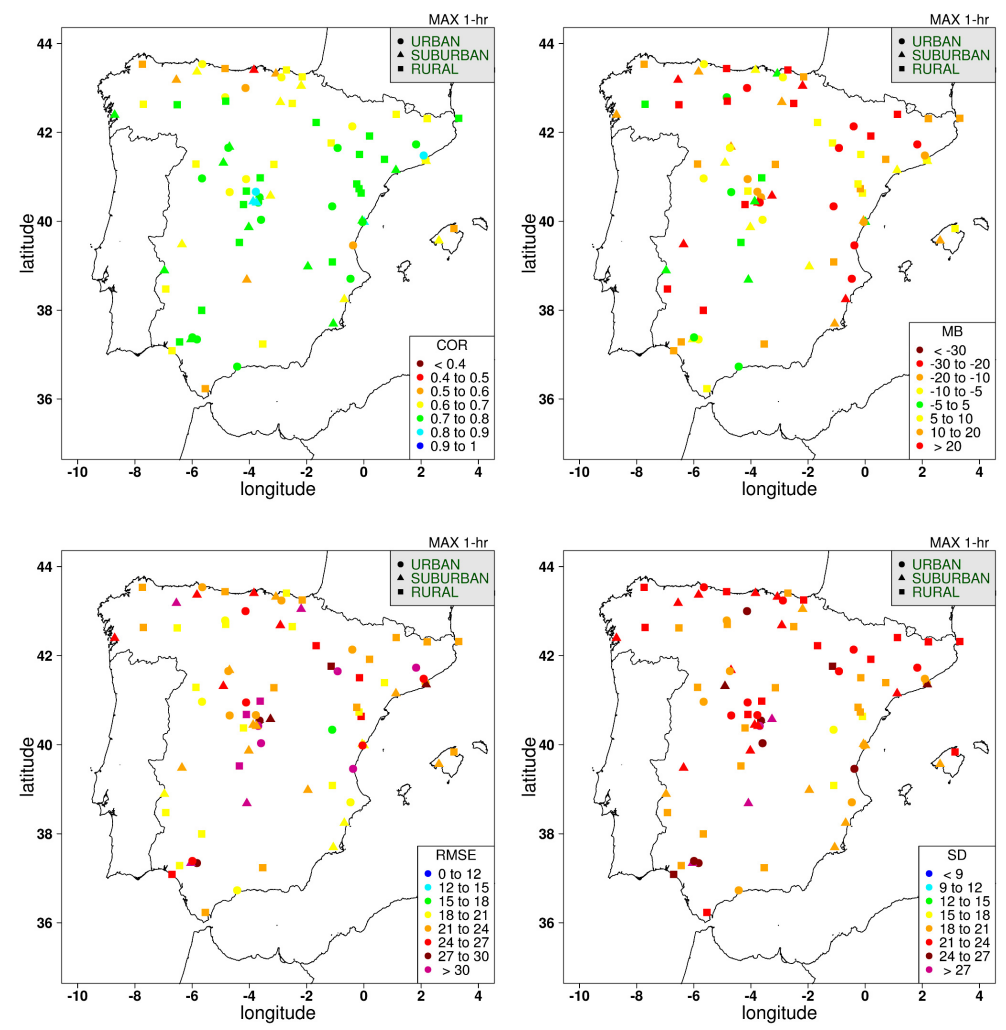

\section{GMDD}

4, 343-384, 2011

\section{Ground-level ozone concentration over Spain}

V. Sicardi et al.

\begin{tabular}{|c|c|}
\hline \multicolumn{2}{|c|}{ Title Page } \\
\hline Abstract & Introduction \\
\hline Conclusions & References \\
\hline Tables & Figures \\
\hline & \\
\hline I4 & \\
\hline 4 & \\
\hline Back & Close \\
\hline
\end{tabular}

\section{Full Screen / Esc}

Printer-friendly Version

Fig. 4. Continued.

Interactive Discussion 

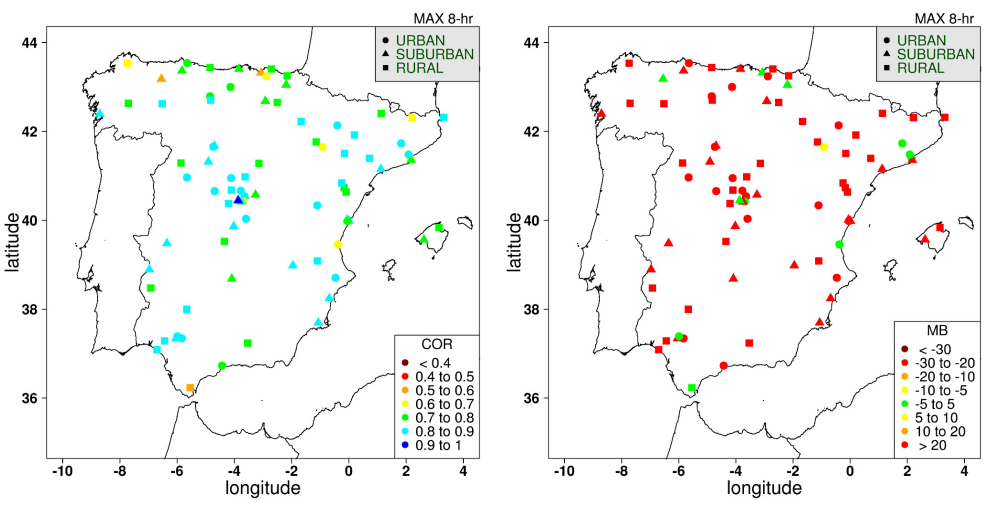

\section{GMDD}

4, 343-384, 2011

\section{Ground-level ozone concentration over Spain}
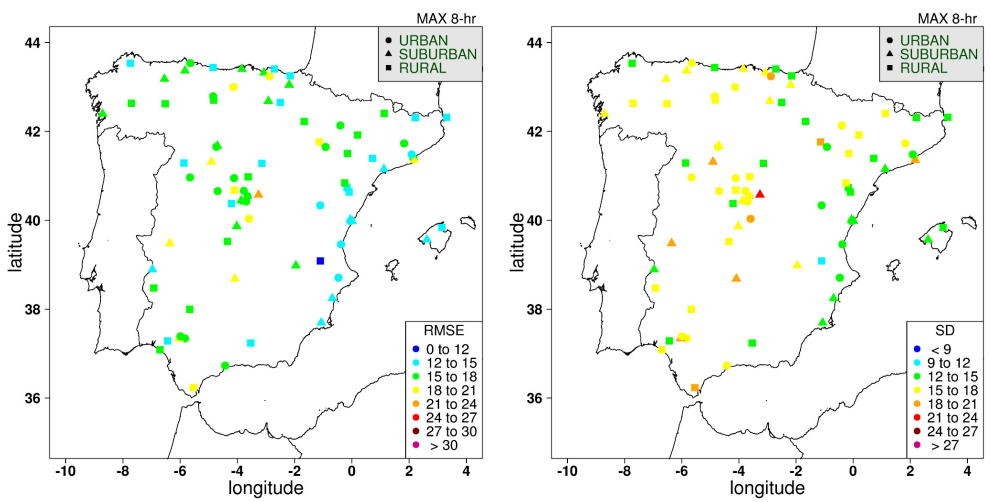

Fig. 5. Spatial distribution of Correlation (COR, ideal value would be 1), Mean Bias (MB, $\mu \mathrm{g} \mathrm{m}^{-3}$ ), Root Mean Square Error (RMSE, $\mu \mathrm{g} \mathrm{m}^{-3}$ ) and Standard Deviation of the error $\left(\mathrm{SD}_{\mathrm{er}}\right)$ for the max. 8-h, for all the RedESP stations, averaged over the year 2004. The air quality monitoring stations are represented according to their type: urban (dot), suburban (triangle), and rural (square).

V. Sicardi et al.

Title Page

\section{Abstract}

Introduction

Conclusions

References

Tables

Figures

14

$\rightarrow$

4

Back

Close

\section{Full Screen / Esc}

Printer-friendly Version

Interactive Discussion 

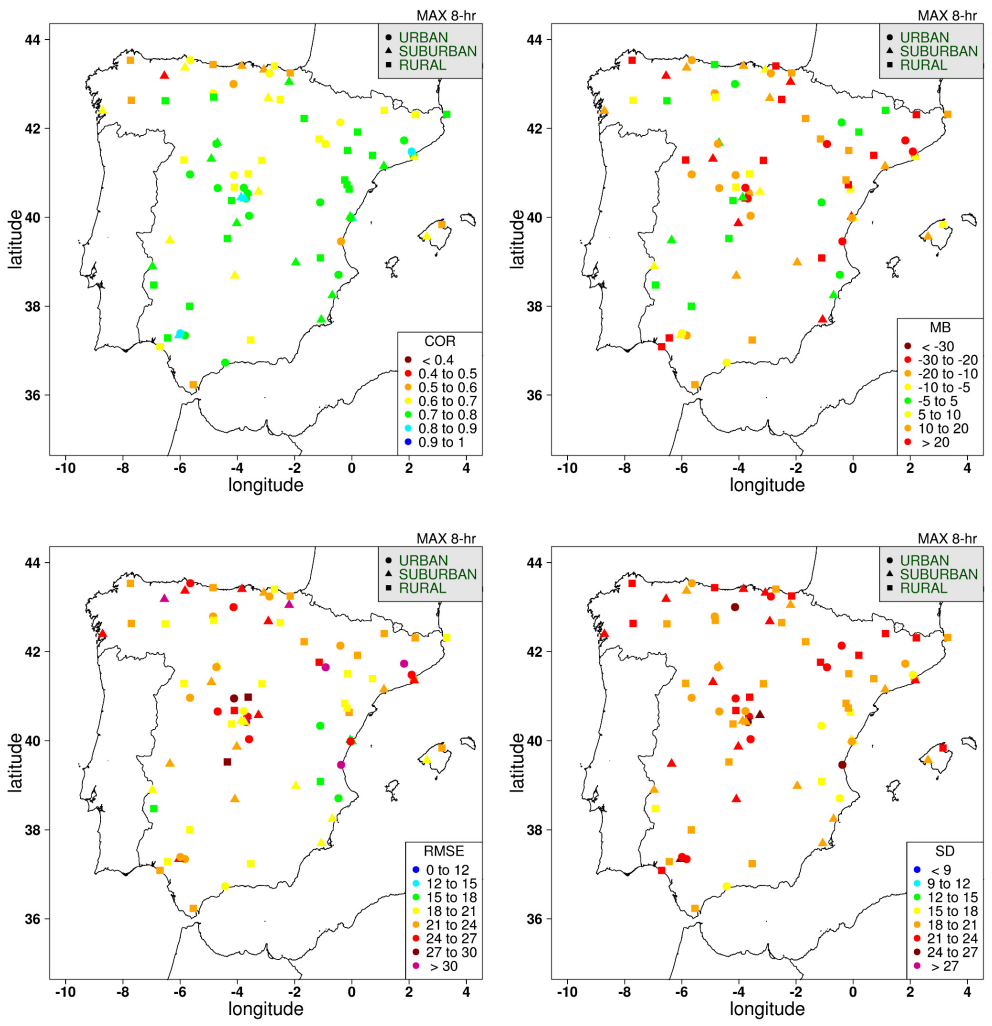

\section{GMDD}

4, 343-384, 2011

\section{Ground-level ozone concentration over Spain}

V. Sicardi et al.

Title Page

\begin{tabular}{|c|c|}
\hline Abstract & Introduction \\
\hline Conclusions & References \\
\hline Tables & Figures \\
\hline I & \\
\hline & \\
\hline Back & Close \\
\hline
\end{tabular}

Full Screen / Esc

Printer-friendly Version

Fig. 5. Continued.

Interactive Discussion 


\section{GMDD}

4, 343-384, 2011
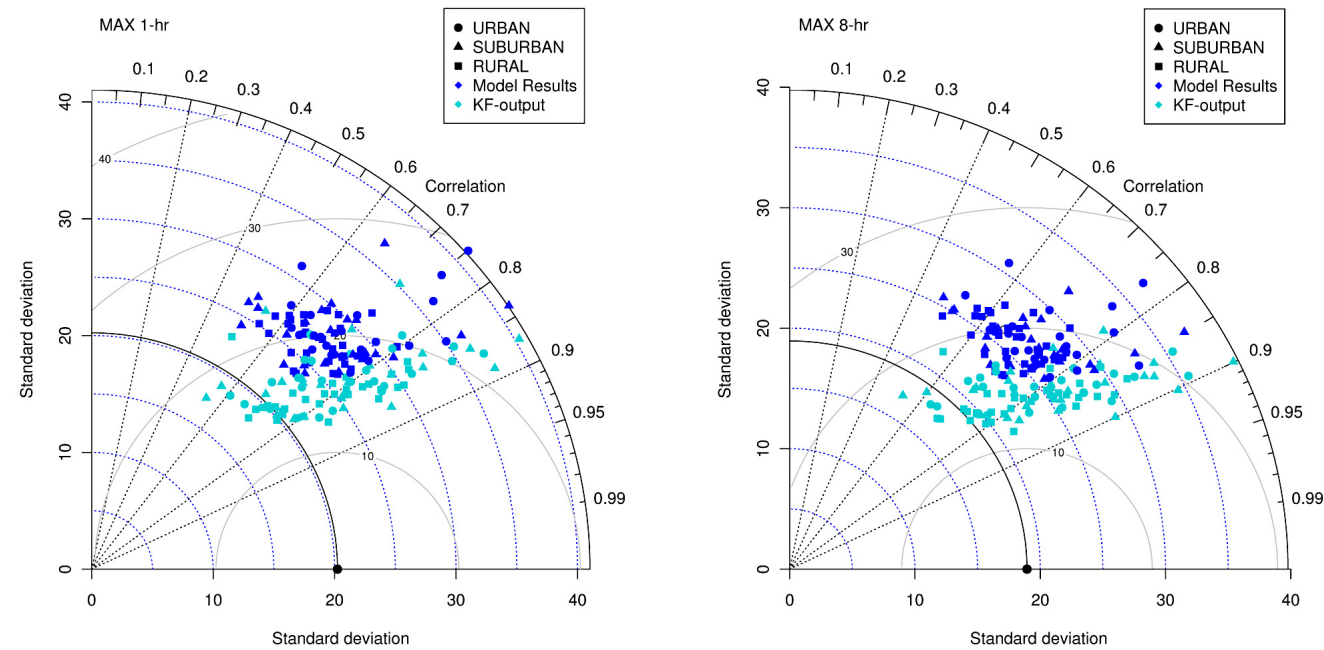

\section{Ground-level ozone concentration over Spain}

V. Sicardi et al.

Fig. 6. Taylor Diagrams for the max. 1-h and max. 8-h. All the considered stations are plotted. The different symbols represent the types of stations. On the plots are depicted the Standard Deviation $\left(\mathrm{g} \mathrm{m}^{-3}\right)$ of the simulated maximum $\mathrm{O}_{3}$ concentration (radius) and the Correlations (cosine of the angle to the horizontal axis). On the horizontal axis is located the standard deviation of the observed values, the closest are the points to this value, the better are simulated the values. The statistics are calculated over the year 2004.

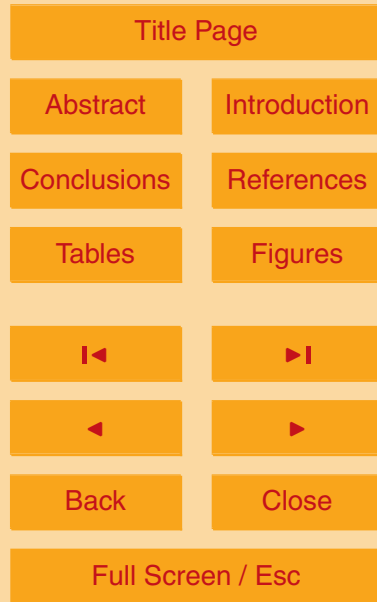

Printer-friendly Version

Interactive Discussion 

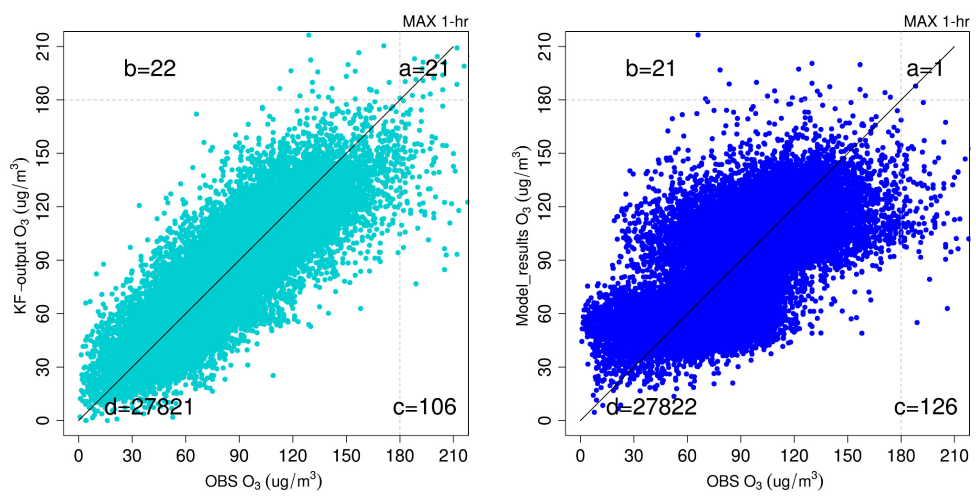

GMDD

4, 343-384, 2011

\section{Ground-level ozone concentration over Spain}
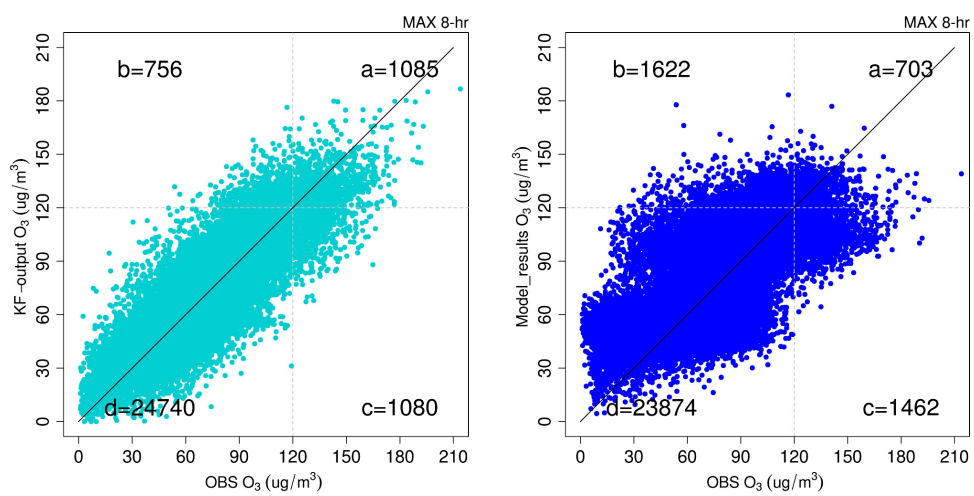

Title Page

Abstract

Introduction

Conclusions

References

Tables

Figures

14

-1

4

Back

$\rightarrow$

\section{Full Screen / Esc} stations considered. The plotted values are on hourly bases. On the plots are depicted the threshold limit $120 \mathrm{\mu g} \mathrm{m}^{-3}$ and $180 \mathrm{\mu g} \mathrm{m}^{-3}$ as established by the EU for the max. 1-h and max. 8-h respectively. The letters $a, b, c, d$ represent the exceedances that did occur (hits), the exceedances that did not occur (false alarms), the exceedances that were not predicted but observed (misses), and the exceedances that did not occur and were not predicted respectively (correct negatives), see Sect. 4.2.

Printer-friendly Version

Interactive Discussion 


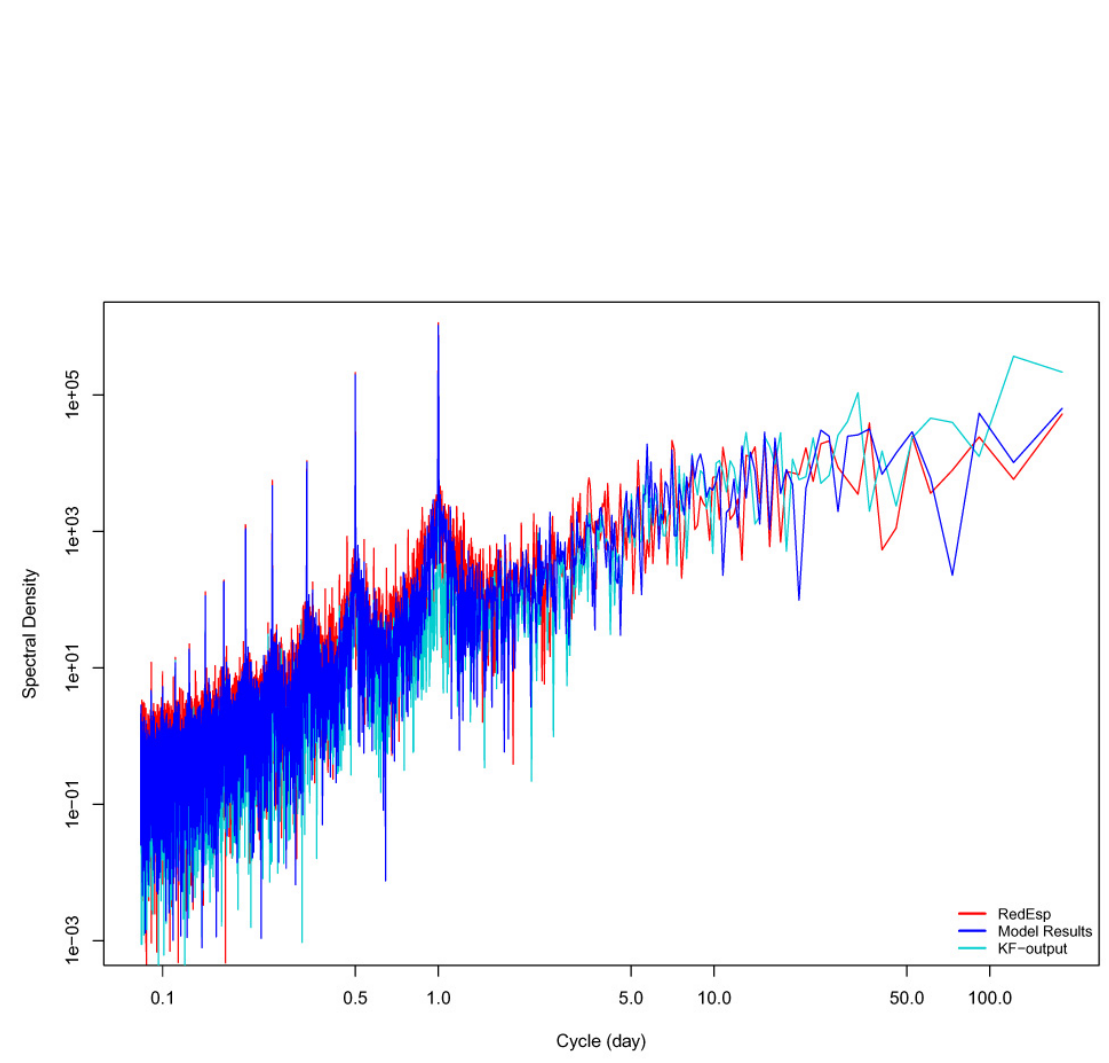

Fig. 8. Spectral analysis of daily $\mathrm{O}_{3}$ concentrations averaged for the whole year averaged over all the stations. The spectral power of the observations (red), model results (blue) and KF-output (bright blue) are compared. The axes are on logarithmic scale.

\section{GMDD}

4, 343-384, 2011

\section{Ground-level ozone concentration over Spain}

V. Sicardi et al.

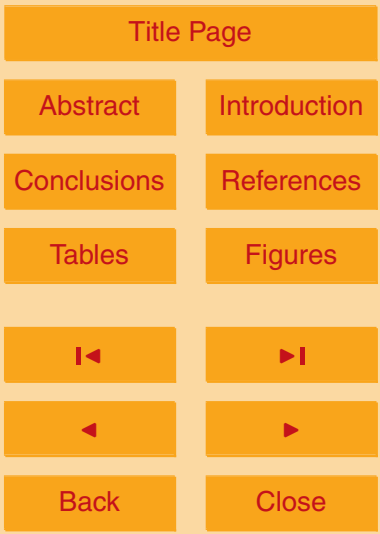

Full Screen / Esc

Printer-friendly Version

Interactive Discussion 


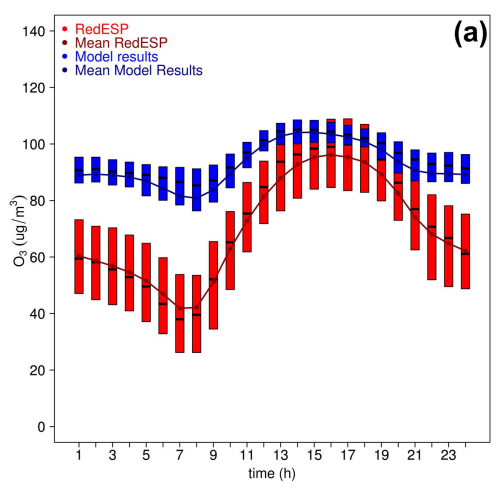

a)

\section{GMDD}

4, 343-384, 2011

\section{Ground-level ozone concentration over Spain}

V. Sicardi et al.

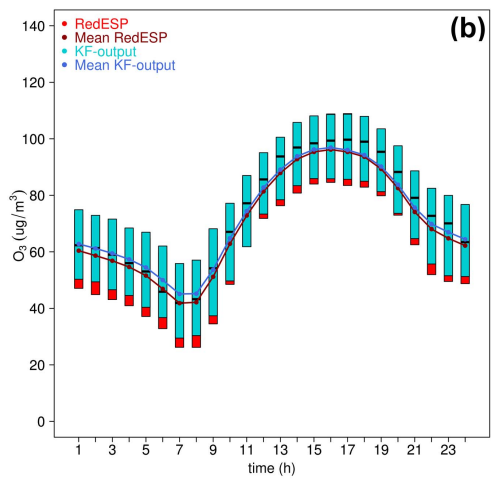

Title Page

Abstract

Introduction

Conclusions

References

Tables

Figures

14

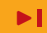

4

Back

Close

\section{Full Screen / Esc} RedESP stations. Model results are represented in (a) and KF-output in (b). The box plots represent the median, the 75th percentile (top) and the 25th percentile (bottom). The overplotted lines represent the mean concentrations. 